\title{
Vascular depression consensus report - a critical update
}

\author{
Howard J. Aizenstein ${ }^{1}$, Andrius Baskys², Maura Boldrini ${ }^{3,4}$, Meryl A. Butters ${ }^{5}$, Breno S. Diniz ${ }^{6}$, Manoj Kumar Jaiswal ${ }^{3,7}$, \\ Kurt A. Jellinger ${ }^{8^{*}}$, Lev S. Kruglov ${ }^{9}$, Ivan A. Meshandin ${ }^{10}$, Milija D. Mijajlovic ${ }^{11}$, Guenter Niklewski ${ }^{12}$, Sarah Pospos ${ }^{2}$, \\ Keerthy Raju ${ }^{13}$, Kneginja Richter ${ }^{12,14}$, David C. Steffens ${ }^{15}$, Warren D. Taylor ${ }^{16,17}$ and Oren Tene ${ }^{18,19}$
}

\begin{abstract}
Background: Vascular depression is regarded as a subtype of late-life depression characterized by a distinct clinical presentation and an association with cerebrovascular damage. Although the term is commonly used in research settings, widely accepted diagnostic criteria are lacking and vascular depression is absent from formal psychiatric manuals such as the Diagnostic and Statistical Manual of Mental Disorders, $5^{\text {th }}$ edition - a fact that limits its use in clinical settings. Magnetic resonance imaging (MRI) techniques, showing a variety of cerebrovascular lesions, including extensive white matter hyperintensities, subcortical microvascular lesions, lacunes, and microinfarcts, in patients with late life depression, led to the introduction of the term "MRI-defined vascular depression".

Discussion: This diagnosis, based on clinical and MRI findings, suggests that vascular lesions lead to depression by disruption of frontal-subcortical-limbic networks involved in mood regulation. However, despite multiple MRI approaches to shed light on the spatiotemporal structural changes associated with late life depression, the causal relationship between brain changes, related lesions, and late life depression remains controversial. While postmortem studies of elderly persons who died from suicide revealed lacunes, small vessel, and Alzheimer-related pathologies, recent autopsy data challenged the role of these lesions in the pathogenesis of vascular depression. Current data propose that the vascular depression connotation should be reserved for depressed older patients with vascular pathology and evident cerebral involvement. Based on current knowledge, the correlations between intra vitam neuroimaging findings and their postmortem validity as well as the role of peripheral markers of vascular disease in late life depression are discussed.

Conclusion: The multifold pathogenesis of vascular depression as a possible subtype of late life depression needs further elucidation. There is a need for correlative clinical, intra vitam structural and functional MRI as well as postmortem MRI and neuropathological studies in order to confirm the relationship between clinical symptomatology and changes in specific brain regions related to depression. To elucidate the causal relationship between regional vascular brain changes and vascular depression, animal models could be helpful. Current treatment options include a combination of vasoactive drugs and antidepressants, but the outcomes are still unsatisfying.
\end{abstract}

Keywords: Late-life depression, Vascular depression, Structural neuroimaging, Cerebrovascular lesions, White matter lesions, Clinicopathological correlations, Peripheral markers, Neuropathology

\footnotetext{
* Correspondence: kurt.jellinger@univie.ac.at

${ }^{8}$ Institute of Clinical Neurobiology, Alberichgasse 5/13, Vienna A-1150, Austria

Full list of author information is available at the end of the article
} International License (http://creativecommons.org/licenses/by/4.0/), which permits unrestricted use, distribution, and reproduction in any medium, provided you give appropriate credit to the original author(s) and the source, provide a link to the Creative Commons license, and indicate if changes were made. The Creative Commons Public Domain Dedication waiver (http://creativecommons.org/publicdomain/zero/1.0/) applies to the data made available in this article, unless otherwise stated. 


\section{Background}

Depressive symptoms in the elderly are common; subsyndromal depression rates in community-dwelling older adults are estimated at 12-30\%, compared with 2-5\% for major depressive disorder (MDD) as defined in the Diagnostic and Statistical Manual of Mental Disorders, fourth edition, text revised (DSM-IV-TR) [1-3]. Although the risk of a depressive episode in the elderly is usually lower than that observed in younger adults [4], the consequences and prognosis of depression in an older population are usually worse. Increasing age in depressed persons accounts for an unfavorable clinical course with higher relapse rates [5], worse treatment response, and incomplete functional recovery [6].

Depression in the elderly is often referred to as latelife depression (LLD), commonly defined as any depressive episode occurring at age 65 or later, regardless of age of onset. LLD can either be late-onset depression (LOD), when the first lifetime depressive episode began after age 65 (some studies place this cut-off at 50 or 60 years of age). In contrast, early-onset depression (EOD) means that an older adult has experienced recurrent depressive episodes with a first episode occurring earlier in life. LLD is of great interest because of its clinical significance and complex basis, which may affect the outcome in the depressed elderly and increase the risk of cognitive impairment and poor quality of life [7-10].

In contrast to depressive disorders in younger adults, LLD is associated with cerebrovascular comorbidities and microvascular lesions, as represented in particular by white matter hyperintensities (WMHs) on structural magnetic resonance imaging (MRI), subcortical lacunes, microinfarcts and microbleeds, but also frontal and temporal (hippocampal) gray matter changes/atrophy, neurodegenerative pathologies, and related biochemical changes [11]. Due to its "organic basis", these etiological factors were used to identify the disorder - through the old concept of "atherosclerotic depression" [12] to the more recent term of "vascular depression" (VaDep). In 1997, Alexopoulos et al. [13] suggested the "VaDep hypothesis", which argues that cerebrovascular disease (CVD), including small vessel ischemic changes, may predispose, precipitate, or perpetuate some geriatric depressive symptoms as a consequence of structural damage to frontal-subcortical circuits, with disruption of cortico-striato-pallido-thalamo-cortical pathways as their underlying systems [13-16] (Fig. 1). Newer MRI based studies argue that VaDep accounts for up to $50 \%$ of MDD cases in the elderly [17]. Boosted by modern neuroimaging techniques, Krishnan et al. [18] coined the entity of "MRI-defined VaDep", which by definition includes CVD findings on MRI. Patients with VaDep were suggested to have a distinct clinical and neuropsychological profile and a positive association with hypertension

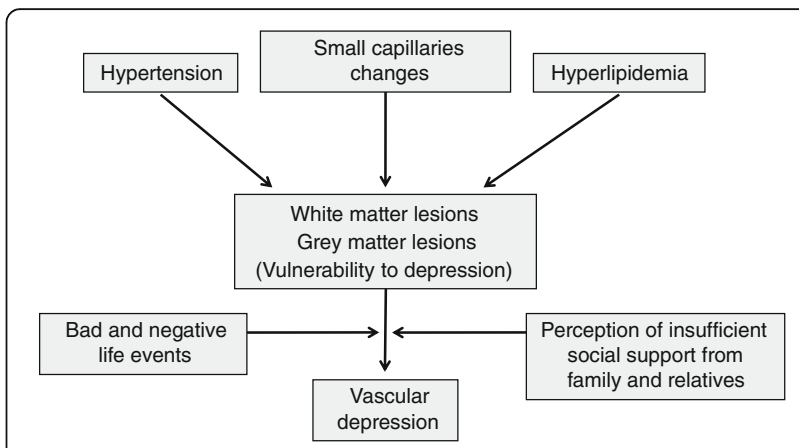

Fig. 1 Flow chart of possible mechanism of vascular depression (adapted from [233])

[19], supporting the notion that VaDep represents a unique and valid subtype of LLD [20-22], although this has not been confirmed by others [23-27]. The MRI literature supporting the VaDep hypothesis shows that loss of brain volume and white matter integrity are associated with poor clinical treatment outcomes [28, 29]. Individuals with VaDep are at greater risk to develop cognitive impairment, more likely related to vascular dementia than to Alzheimer's disease (AD) [30]. However, recent data showed that VaDep is not a risk factor for AD [31, 32], although older cognitively unimpaired patients with depressive episodes may have more underlying AD pathology, in particular $\beta$-amyloid deposition $[33,34]$. In general, depression in vascular dementia is clinically different from that in $\mathrm{AD}$ [30]. Although MDD is mainly diagnosed, treated, and studied by psychiatrists, the DSM-IV-TR, and the newer DSM-V, do not acknowledge the diagnosis of VaDep and do not address its treatment-resistant course. In addition, MRI is usually used to rule out organic causes for psychiatric symptoms rather than to validate a psychiatric diagnosis. Thus, it is clear why the definition of this entity and agreed diagnostic criteria remain elusive, a fact that complicates studies in this field and the introduction of therapeutic options.

The relationship between structural and biochemical cerebral changes contributing to brain network dysfunctions in VaDep is also not fully understood, and recent neuropathological findings even challenged the validity of the VaDep hypothesis (for a review, see [31]).

The aims of this Consensus Report are to examine the current evidence for the neurobiology of VaDep. It focuses on neuroimaging and neuropathological data to consider the relevance of cerebrovascular changes in the pathogenesis of LLD, but also considers the role of peripheral markers in VaDep, the differences in biological substrates based on age of depression onset, and the therapeutic options. Based on this overview, we present ideas about future research in this still incompletely elucidated area of VaDep and make proposals for future studies in order to clarify the relations between LLD and 
CVD that may promote further consensus and approval of VaDep; some of these issues have been reviewed recently $[7,9,17,28,31,35-42]$. The issue of post-stroke depression will not be discussed, since it has been reviewed by a different consensus group.

\section{Methods}

Using a comprehensive search of PubMed (MEDLINE) from January 1990 until November 30, 2015, the current literature was critically reviewed on the association between VaDep and microvascular burden, gray and white matter lesions, and other structural brain changes resulting in brain network dysfunction detected by MRI, as well as neuropathological studies.

Approximately 4000 articles were reviewed, but studies were only included if they satisfied the following criteria: (1) the patient population had a diagnosis of LLD and/or VaDep, (2) diffusion tensor imaging was the imaging technique used, (3) contained a vascular depression hypothesis, and (4) publication in English. Additionally, references from the selected papers were evaluated and included if they were found to be relevant to the focus of this systematic review. Exclusion criteria were publication prior to 1990, and articles discussing post-stroke depression, depression in $\mathrm{AD}$, vascular dementia, and other dementias. Furthermore, the findings by the members of the consensus report summarized in the abstracts of the 9th International Congress on Vascular Dementia 2015 were included in order to supplement the data in the literature. To ensure the quality, a faceto-face meeting of the group of multidisciplinary experts (BSD, MKJ, KAJ, MDM, KR, TO) was followed by extensive e-mail correspondence among the larger group of co-authors. In order to actualize this report, the relevant literature until August 30, 2016, was included.

\section{Results}

\section{Clinical features of VaDep}

There is considerable evidence to suggest that the clinical manifestations of VaDep are distinct from nonVaDep in the elderly (Table 1 ). This may be related to differences in age of depression onset [20, 43, 44], as individuals with VaDep tend to have a later age of initial onset of depression [19]. However, even individuals with EOD may be at risk of transitioning to VaDep since some studies have implied a bi-directional link between vascular disease and depression $[45,46]$.

The clinical presentation of VaDep is characterized by psychomotor slowing, lack of initiative and apathy, absence of a family history of depression, and a medical history of hypertension. Cognitive impairment is also common, particularly executive dysfunction and impaired processing speed. Functional disability may also be disproportional to the severity of cognitive impairment. Overall, patients with VaDep have greater cognitive impairment and disability than individuals of the same age with nonvascular depression $[16,19,28,36,37,47,48]$.

Observations of VaDep being associated with greater disability, poorer outcomes, and executive dysfunction $[20,21,49]$ led to a reconceptualization of VaDep, with subsequent proposals of the "depressive-executive dysfunction syndrome" $[37,50,51]$ or "depression-cognitive impairment disease" [52]. However, although these conceptualizations overlap, they are not necessarily synonymous. In depressed older patients, cerebral vascular burden is related to slower processing speed even in the absence of manifest generalized vascular disease [53]. Depressed older people with lacunar infarcts in deep white matter are characterized by more "motivational" problems than those with no vascular disease $[41,54]$. A comparison of subcortical ischemic depression and depressive-executive dysfunction syndrome

Table 1 Clinical features of vascular depression (VaDep) and non-VaDep

\begin{tabular}{l} 
Clinical features of VaDep \\
\hline Depression occurring at age 65 years or later \\
Absence of family history \\
Executive dysfunctions, loss of energy, subjective feeling of sadness, \\
anhedonia, psychomotor retardation, motivational problems, reduced \\
processing speed and visuospatial skills, deficits in self-initiation, lack \\
of insight; depressive symptomatology may not meet criteria for any \\
mood disorder requested in DSM-V \\
Higher cardiac illness burden, increased rates of vascular risk factors \\
(hypertension, etc.) \\
Higher risk for cognitive decline and progression to dementia
\end{tabular}

Fluctuating course of cognitive impairment due to progression of white matter hyperintensities

Greater treatment resistance and poorer outcome

Associated with increased mortality

Clinical features of non-VaDep

Depression occurring at age 50 to 60 years

Occasional family history

Sadness, depression according to DSM-V diagnostic criteria, increased suicidality, reduced verbal fluency

Lower or same cardiac illness burden and rates of vascular risk factors (hypertension, etc.)

Lower or similar risk for cognitive decline and progression to dementia

Lower or same treatment resistance and outcome(?) 
showed no significant differences in predicting functional disability [55].

Other clinical factors distinguish VaDep from nonvascular depression, including age, higher cardiac illness burden, and greater deficits in depression symptoms of self-initiation and concentration [56], while loss of libido, agitation, risk of suicidal activity, and a family history of mental illness, were associated with EOD and not specifically with VaDep [19]. While loss of energy and lethargy, apathy, and executive dysfunction were frequently observed in patients with VaDep [57], other symptoms, namely psychomotor retardation and anhedonia, were not significantly associated with vascular risk factors [24]. However, suicidal patients scored higher in the vascular cumulative illness rating scale [58]. There may also be population differences. In a multiethnic clinical sample VaDep was overrepresented among African Americans, probably due to higher rates of cardiovascular disease, hypertension, and stroke [59].

This is concordant with other work associating increased risk of depression in populations with vascular disease. For example, people with peripheral artery disease have a higher incidence of depressive symptoms than those without. Further, in peripheral artery disease, depressive symptoms are associated with increased cardiovascular mortality [60]. Depression and vascular disease are both common among the elderly, and cardiac dysfunction in association with depression is well documented [46, 61, 62]. These observations may provide clues about the mechanistic relationships, as depression-associated changes of peripheral vascular resistance are essential for the association of MDD with cardiovascular disease [63, 64].

Depression may also contribute to adverse vascular health outcomes. There is a strong association between baseline depression scores and later cardiovascular mortality in hypertensive elderly people [65-68]; depressive states are considered a potential CVD mortality risk factor [69]. Meta-analyses of longitudinal cohort and case-control studies reporting depression at baseline and cardiovascular disease outcomes at follow-up identified MDD as the most important risk factor for developing cardiovascular disease, although this evidence is related to a high level of heterogeneity [70]. Depressionlike behaviors have been observed in a rat model of chronic cerebral hypoperfusion [71]. Depression is a strong risk factor for stroke in middle aged women [72], and elderly patients with high levels of depressive symptoms showed an increased risk of stroke events [62]. Unsurprisingly, as accepted diagnostic criteria for VaDep are lacking, there is no epidemiological outcome data about VaDep in the general population.

While loss of energy and lethargy, apathy, and executive dysfunctions are frequently observed in patients with VaDep [57], other symptoms, namely psychomotor retardation and anhedonia, are not significantly associated with vascular risk factors [24]. However, suicidal patients scored higher in the vascular cumulative illness rating scale [58].

\section{VaDep and cognitive impairment}

Depressive symptoms in old age flag an increased likelihood of cognitive decline in later life [10,73]; the effect is particularly high in individuals with depression and vascular disorder [9]. Depression and vascular disorder are highly prevalent among elderly subjects with mild cognitive impairment (MCI) and in cognitively normal elders, with an increased risk of developing MCI [74], particularly in those with higher cerebral amyloid burden [75]. Recent meta-analyses showed that LLD increases the risk of $\mathrm{AD}$ by $65 \%$ and vascular dementia by $150 \%$ compared to non-depressed older adults [30]. The relationship between LLD and risk of dementia is also particularly relevant among older adults with $\mathrm{MCI}$, since the cooccurrence of depressive symptoms and MCI leads to an increased risk of dementia by approximately $30 \%$ compared to MCI individuals with no depression [76].

Nevertheless, not only the presence of depressive symptoms is important to determine the risk of dementia in LLD/VaDep. Recent longitudinal studies, with up 10 years of follow-up, demonstrated that persistently high levels or increasing levels of depressive symptoms are the most important predictors of dementia in LLD $[77,78]$. The association with depressive symptoms is stronger for the MCI subtype with memory impairment [79], but this was independent of underlying vascular disease [80-82]. Some studies suggested an association between white matter microstructural damage and depressive symptoms in MCI patients with small vessel disease [74, 83], whereas others showed no association between depressive symptoms and the rate of incident MCI [84]. The path from CVD to VaDep and to vascular dementia appears to be likely reciprocal and not direct or sequential [85], whereas others suggested that depression is an independent risk factor for subsequent vascular dementia [86]. There are multiple pathways to poor cognitive outcomes and therefore the relationship reflecting either a causal effect of depression on cognitive decline, or a common cause, or both, should be further explored [25, 87]. Older patients with greater WMH volume appear to progress to dementia at a similar rate as those who were never depressed with similar WMHs [40]. However, individuals with LLD are, in general, at greater risk of developing vascular dementia as compared to $\mathrm{AD}$ [30], and depression in vascular dementia is quantitatively and qualitatively different from that in AD [88]. Recent clinicopathological studies showed that depressive symptoms in old age associated with cognitive decline were independent of the neuropathologic hallmarks of dementia, 
and none of the neuropathological markers (CVD, ADrelated pathology) were related to the level of depressive symptoms or changes in symptoms over time [89-91]. Despite frequent neuroimaging evidence in favor of a possible causal link between depressive symptoms and cognitive impairment in old age, neuropathological data showed that LLD and VaDep are not a risk factor for AD pathology and that cognitive impairment in old age may be due to a variety of pathological and molecular changes [25, 31, 32]. According to a recent clinical study, the presence of depressive symptoms in amnestic MCI patients is not predictive of conversion to dementia [92]. On the other hand, older, cognitively normal patients with depressive episodes were found more likely to have an underlying AD pathology, in particular $\beta$-amyloid deposition [33, 34]. However, there are inconsistent results for plasma and/or cerebrospinal fluid levels of soluble $\beta$-amyloid 42 in LLD [93].

\section{Structural brain abnormalities}

Structural and functional imaging studies provide information about the underlying (micro) structural changes in VaDep, including localization and anatomical size and shape of gray and white matter lesions [94].

\section{White matter lesions}

MRI-defined VaDep requires evidence of cerebrovascular changes on neuroimaging, including WMHs [19]. The validity of this subtype, characterized by voxelbased morphometry and diffusion tensor imaging MRI as well as executive dysfunction, was confirmed by several studies [35, 37, 95]. Microstructural brain lesions, especially WMHs, are more frequently found in patients with LLD compared to controls [96-102]. They involve, in particular, white matter tracts underlying emotional and cognitive function, i.e., left superior longitudinal fascicle, cingulum bundle, and frontal projections to the corpus callosum [103-105], disrupting frontal and frontal-to-limbic white matter tracts [106]. The importance of deep WMHs and subcortical lacunar infarcts on the risk of depressive symptoms [107-109] and a strong relationship between depression and WMH volume [110] were emphasized. A recent study showed that diffuse WMHs are one of the major factors that cause apathy and have negative effects on quality of life [111], while others could not demonstrate any significant association between WMH progression and depression at baseline [112]. A multicenter longitudinal study showed that WMHs predated the development of depressive symptoms in later life. Greater WMH severity is a critical risk factor predicting future depression risk, which supports the VaDep hypothesis [17]. The severity of WMHs may serve as a biomarker for LLD [113], although the results of a European multicenter study (LADIS) showed that baseline severity of WMHs no longer predicted depressive symptoms at 3 years or incident depression [114]. A strong association between deep WMHs and depression compared to periventricular ones was observed [107]. A recent study showed that individuals with extensive WMHs at baseline had a high risk of developing severe depressive symptoms, with the relationship strengthening in the absence of cardiovascular disease. In contrast, when depressive symptoms or antidepressant prescription was the outcome, larger brain volume and temporal lobe volume, but not WMH, were negatively associated with the development of depression [115].

Systematic reviews reported a four-fold higher prevalence of deep and periventricular WMHs in LOD/LLD subjects than in those with EOD and healthy controls $[98,116]$. Together with a more frequent presence of cardiovascular risk factors (hypertension, dyslipidemia, vascular co-morbidity, diabetes mellitus) [117-120], and a history of CVD, a higher burden of WMHs was proposed to be a diagnostic criterion for VaDep or subcortical ischemic depression [19]. Deep WMHs are associated with a more fluctuating but not more severe course of depression. Lacunar infarcts do not correlate with severity or course of depressive symptoms, while periventricular WMHs are associated with poorer executive function [54], and large confluent WMHs with cognitive impairment and disability [121]. Greater longitudinal increases in WMH volume are associated with more persistent depressive symptoms [122, 123]. All WMHs, except the least severe, have been shown to have a negative effect on depression outcome and, together, both deficits in neuropsychological function and severity of WMHs predict worse outcome [119]. The WMH volume in the frontal lobe conferred a risk of comorbid depressive disorder in AD, which implies that comorbid depression in $\mathrm{AD}$ may be attributed to vascular causes, and does not essentially differ from VaDep without AD-related changes [124]. Others suggested that dysfunctions in left-sided functionally salient cortical regions and relative preservation of deficit awareness, provided by the right hemisphere, may explain depressive symptoms in the initial clinical stages of AD [125].

\section{Gray matter changes}

Structural abnormalities in LLD also involve gray matter reduction in the bilateral orbitofrontal and medial frontal cortex, subcallosal gyrus, hippocampus, parahippocampus, amygdala, insula, and anterior cingulate cortex, and cortical thinning and volume reduction in lentiform nucleus (for a review, see [31, 32, 126, 127]), indicating that these alterations within the fronto-striato-limbic network and disrupted orbitomedial prefrontal limbic network play a key role in the pathophysiology of VaDep [47, 128-132]. In very old adults with depression, loss of grey matter 
volume was most significant in the bilateral insula and anterior cerebral cortex, supporting a cerebrovascular pattern of LLD [133]. These changes, together with WMHs, are associated with both depression and cognitive decline and may precede the incidence of both disorders in elders by 10 years [134], suggesting an etiological pathway from ischemia to increased depressive burden [133]. The currently largest worldwide effort to identify subcortical brain alterations showed reduction of hippocampal and amygdala volumes in recurrent and/or early onset MDDs, moderated by age of onset and first episode versus recurrent episode status [135]. Later age at onset of depressive symptoms in LLD subjects is associated with smaller left anterior cingulate thickness, and more white matter and subcortical gray matter hyperintensities [128]. The greater burden of depressive symptoms was significantly related to low fractional anisotropy in MRI of white matter underlying the right ventral anterior cingulate in depressed older adults with vascular disease [136].

The relationship between vascular disease and these findings in LLD/VaDep is not entirely clear, and both constructs apparently share many neuropathophysiological characteristics and changes, although VaDep appears more related to cerebrovascular rather than to other types of brain lesions [137-139]. Both gray and white matter abnormalities in VaDep indicate that four major neurocircuits are involved, namely default mode, cognitive control, frontolimbic, and corticostriatal networks [140-143]. The default-mode network includes several brain regions that are active during rest and inhibited during goal-directed tasks [140, 142]. It consists of the medial prefrontal cortex, posterior cingulate cortex, precuneus, and medial temporal lobe, and its functions include self-prospecting, internal monitoring, memory retrieval, future planning, and the theory of mind. Depression is associated with decreased default-mode network activity during a cognitive or emotional task or increased activity during negative rumination [142]. Specifically, in LLD, default-mode activity is increased in the subgenual cingulate and thalamus region [140].

The cognitive control network consists of the dorsolateral prefrontal cortex, the dorsal anterior cingulate cortex, and the posterior parietal cortex, and is involved in attention-dependent executive tasks such as decisionmaking, working memory, and task switching [142]. An impaired cognitive control network has also been associated with impaired cognition in depression [142].

The frontolimbic or affective network consists of the amygdala, the subgenual anterior cingulate cortex, hypothalamus, orbitofrontal cortex, and nucleus accumbens, with the main functions of processing emotion, regulating the emotion-mood relationship, and mediating motivated behaviors. Specifically, decreased amygdala volume, decreased orbitofrontal cortex volume, and a disrupted uncinate tract, which connects amygdala and hippocampus to the frontal centers, have been demonstrated in LLD [142].

Corticostriatal networks connect frontal regions to basal ganglia and thalamus; their function primarily includes the mediation of motor and executive control and emotional behavior [141]. However, other volumetric differences observed in LLD may be influenced by vascular disease, but could also reflect premorbid vulnerabilities or occur through other (neurodegenerative) pathways. If unrelated to vascular disease, these structural differences could thus serve as vulnerability factors contributing to the risk of depression.

\section{Cerebrovascular lesions}

Review studies indicate a higher frequency of depression in older people with cardiovascular disease with or without a cerebrovascular component, and suggest the possibility of a bidirectional relationship between vascular disease and depression, although the association between vascular risk factors and LLD may not be consistent [21] and the causality in the individual case may be difficult to establish. In depressed older persons, vascular burden was related to slower progressing speed also in the absence of manifest vascular disease [53]. A large body of neuroimaging data supports the notion that microvascular burden and WMHs may be key determinants of depressive episodes in late life [144]. LLD patients had a higher prevalence of silent brain infarctions, subcortical lacunes, and microbleeds, especially in the left hemisphere and in basal ganglia, compared to control groups. These lesions presented as independent risk factors for LLD [145], while microbleeds in the left hemisphere were not associated with EOD [146]. WMHs and lacunar infarcts may be non-specific vascular lesions in depressive disorders, while association of cerebral microbleeds with more severe forms of depression may indicate impaired brain iron homeostasis or episodes of cerebrovascular extraversion, which may play a role in depression etiology [147]. Microbleeds were associated with LLD but not with EOD [146]; these lesions and WMHs were associated with cerebral small vessel disease (CSVD) and reduced cerebral blood flow [148], which predicted depressive disorder in healthy older adults [149]. Depressive symptoms were seen in 10.1-39.8\% of patients with CSVD [2, 150], and patients with silent cerebral infarcts and chronic heart failure had an increased prevalence of MDD compared to those without chronic heart failure [151]; further, minor cerebrovascular incidents predisposed patients to LLD/ VaDep [152]. Lacunar infarcts in deep white matter were associated with greater psychomotor retardation, motivation and energy loss, depressed mood, and cognitive decline, presumably due to disruption of frontal-subcortical networks [153, 154], while others suggested that apathy, 
but not depression in CSVD, is related to damage in circuits associated with emotion regulation [155]. Interestingly, while microvascular lesions tended to have a deteriorating course once diagnosed, there are no data supporting an exact parallel deterioration in VaDep symptomatology. Rather, VaDep could potentially remit with treatment, while WMHs do not (despite more than $50 \%$ of older adults with late-life MDD failing to respond to initial treatment with first-line pharmacological therapy) [156].

\section{Other pathogenetic features}

Recent studies using a multimodal biomarker approach have indicated relationships between depression, WMHs, and abnormalities in biomarkers related to inflammatory processes, including higher TNF receptor- 2 and IL-1 $\beta$ levels, endothelial dysfunction, astrocytic abnormalities, platelet activation, control of blood clotting processes, lipid homeostasis, and reduced neurotrophic support, indicating the relevance of vascular disease and other factors in the pathogenesis of LLD [157-165]. Nonvascular factors may also contribute to VaDep. The same genetic, epigenetic, and environmental factors that contribute to EOD continue to confer vulnerability for depression onset in later life [166]. Although immune and endocrine disorders affect vascular risk, they may also increase the risk of depression through independent mechanisms that require further study [167]. More recently, the amyloid hypothesis of LLD was discussed [33, 34].

Recent studies have focused on the role of glia in LLD $[162,168]$, although the mechanisms by which glia are associated with the symptoms of MDD remain unclear. Inflammatory mechanisms and the role of cytokines and other pro-inflammatory markers have been suggested [169] (for a review, see [170]). Gliosis being reduced in EOD brains and increased in LLD suggests that subtle vascular or inflammatory changes may be important in LLD, but further studies are required to explore the complex relationship between WMHs, ischemic damages, and glial pathology in those processes. There is no evidence for a loss of serotonergic neurons or of neuritic pathology in the raphe nuclei of LLD patients [31, 171], while the mesolimbic dopamine system, especially the ventral tegmental area, involved by Lewy bodies and neurofibrillary tangles, may have an important role in LLD symptoms [172].

\section{Neuropathological findings in VaDep}

Postmortem studies in clinically well-documented cases are crucial to elucidate the role of cerebrovascular lesions in LLD since neuropathological findings are heterogeneous [11, 31, 46, 144, 173-176]. The first report on white matter pathology in LLD [177] suggesting that white matter lesions due to microvascular dependent ischemia in the dorsolateral prefrontal cortex are important for cognitive impairment in LLD, has not been confirmed [178]. No association between depression and vascular or microvascular disease has been observed [31, 46, 95, $144,175,179,180]$. These results challenge the "VaDep hypothesis" by indicating that the chronic burden of microvascular lesions may not be a major pathogenic factor for LLD. Further, recent clinicopathological studies did not confirm the hypothesis that subcortical microvascular lesions and cortical microinfarcts may be essential for the development of LLD [11, 31, 95, 144, 174-176, 179-183]. There was also no confirmation for the notion that diffuse WMHs may be associated with long-term depression [184, 185] nor that general and cerebral atherosclerosis may increase the risk of incident depression in older adults (Table 2). Alternatively, it was suggested that both disorders result from a common underlying biological substrate [137]. These studies also showed no definite relationship between LLD and AD pathology, including in cerebral amyloid angiopathy [186], revealing a significant gap in our understanding of the pathobiology of LLD. It should be emphasized that the published findings in VaDep are not consistent and are often complicated by comorbid conditions, and therefore there has been limited success in demonstrating any relationship with many of these pathological changes [31, 176, 187].

\section{Animal models of VaDep}

The chronic mild stress model of depression is well documented [188-191]; it is associated with vascular and endothelial dysfunction [192-194], both of which are risk factors for the development of cardiac disease. Further, depression-like behaviors in a rat model of chronic cerebral hypoperfusion and cerebral ischemia-induced sensitivity to depression, as well as hippocampal vascular endothelial growth factor down regulation after forced

Table 2 Negative neuropathology findings in late-life depression

\begin{tabular}{|c|c|}
\hline Findings & Reference \\
\hline No association with microvascular disease & {$[179]$} \\
\hline $\begin{array}{l}\text { Cerebrovascular pathology (hemorrhages, infarcts, } \\
\text { microinfarcts, lacunes) not more severe than in } \\
\text { non-depressed aged }\end{array}$ & {$[31,175,176,180]$} \\
\hline No increased white matter change & {$[31,176]$} \\
\hline No increased Alzheimer's disease pathology & {$[31,176,180,181]$} \\
\hline $\begin{array}{l}\text { No increased cerebral amyloid angiopathy (but } \\
\text { association between plaque and tangle pathology } \\
\text { and life time depression preceding Alzheimer's } \\
\text { disease diagnosis) }\end{array}$ & {$[182,183]$} \\
\hline No hippocampal sclerosis & {$[31]$} \\
\hline
\end{tabular}


swim stress in mice, all support the clinical hypothesis of VaDep $[71,195,196]$.

\section{Discussion}

\section{Clinicopathological relations in VaDep}

VaDep can be regarded as a distinct subtype of LLD characterized by a specific clinical presentation and an association with vascular risk factors and a variety of cerebrovascular lesions, as shown by structural MRI. The hallmark of MRI-defined VaDep is the presence of WMHs identified in T2-weighted or fluid attenuated inversion recovery sequences. These lesions, associated with CSVD, induce disruptions of frontal-subcortical pathways involved in mood regulation. WMHs are associated with advanced age, cerebrovascular risk factors (diabetes, hypertension, cardiac disease, blood pressure variability, and reduced cerebral blood flow) (for a review, see [38, 121, 197, 198]). The correlation between WMHs and altered default-mode network connectivity supported the role of vascular changes in the etiopathogenesis of VaDep [140, 145] and diminished neuropsychological performance was related to microstructural white matter abnormalities [199]. VaDep is associated with poorer endothelial function, potentially contributing to greater WMH load and basal ganglia microangiopathy [138]. WMHs in patients with LLD, especially within corticosubcortical neural circuits, should be interpreted as the consequence of underlying microstructural dysfunctions affecting brain connectivity, mediating the association between CSVD and depression [38, 139, 200, 201], although not all studies supported the existence of WMHs as assessed by diffusion tensor imaging MRI in VaDep [202-204]. Others, however, suggested that apathy, but not depression, in CSVD is related to damage to cortical-subcortical networks associated with regulation of emotions [155].

Other frequent findings include widespread gray matter reductions related to disorders of the fronto-striatolimbic network. White matter abnormalities, particularly in the fronto-subcortical and limbic networks have been suggested to play a role in LLD even in the absence of essential gray matter changes [47, 94]. However, a recent study of MRI-defined VaDep showed that subjects with high scores of either deep WMHs or subcortical gray matter ratings had an eight-fold higher risk of developing depressive disorders in a 3-year follow-up study [17]. No association between LLD and Framingham vascular risk factors (hypertension, dyslipidemia, diabetes, etc.) was found, although positive relations between depression in elders and cardiovascular disease were observed $[205,206]$. There are various mechanisms by which vascular disease may influence the development and course of depression - mechanistic disconnection, inflammation and hypoperfusion - that link underlying cerebrovascular processes with brain function influencing the development of depression [37].

\section{Prevention and treatment options}

Brain reserve, characterized by educational attainment, may counterbalance the effect of cerebrovascular burden with respect to depressive symptoms, thereby preserving mood in late life [207]. Additionally, since older patients with both depression and vascular risk factors may be at an increased risk for functional decline, they may benefit from management of both these factors and depression [208, 209]. Overall, individuals with VaDep and deficits across cognitive domains may be at higher risk of responding poorly to selective serotonin reuptake inhibitors [119]. Positron emission tomography (PET) studies have demonstrated an increase in cortical glucose metabolism in non-demented and largely never-medicated geriatric depressed patients relative to age-matched controls in anterior and posterior cortical regions in which cerebral atrophy was observed. These regions were hypermetabolic and atrophic and were correlated with depression, which may represent a compensatory response; these findings are in contrast with the decreased metabolism observed in normal aging and neurodegenerative diseases [210]. Possible efficacy in treatment of VaDep with a combination of vasoactive and neurometabolic drugs along with several groups of modern antidepressants (selective serotonin and noradrenaline reuptake inhibitors) has been demonstrated [211]. However, no significant differences were observed in any of the neuroimaging markers (WMH accumulation) nor in treatment outcome over an interval of 12 weeks, which corresponds to the typical length of an antidepressant trial [212]. Further, no differences were found in neuropsychological factor scores [213] nor in treatment outcome between EOD and LOD subjects [128]. Neuroimaging markers may inform treatment by identifying depressed adults likely to remit with pharmacotherapy, an individualized therapeutic dose, and treatment response [29, 39]. In essence, treatment results in VaDep patients are still unsatisfying and, regardless of causal mechanisms, persons with depressive disorders and vascular disease represent a high-risk group for poor treatment response [214]. The prevalence of treatment-resistant LLD was estimated between 26 and 41 per 100 person years [215]. Greater baseline cerebrovascular risk was associated with less improvement in depression severity over time, and after controlling for co-variates, neither executive function nor processing speed predicted outcome [216]. Cardiovascular risk factors and comorbid cerebrovascular changes [217] may moderate pharmacological treatment effects or may even have negative effects in the treatment of VaDep [218]. In addition to the appropriate treatment for depression, screening and optimized management of risk factors 
for cardiovascular and cerebrovascular disease is necessary $[219,220]$. Importantly, some data imply that antihypertensive agents, such as beta-blockers, which are widely used by patients with cardiovascular disease, can cause or worsen depression [221]. Nevertheless, controversies still surround these issues, even after decades of widespread use of these drugs [222]. Targeting LLD in individuals with vascular disorders might lower dementia risk by preventing cerebrovascular changes [9]. New methods in management control rely on large datasets ("big data") of pharmacogenomics, clinical, and pharmacological information and the use of modern mobile applications (apps) for the monitoring of mood and quality of life in individuals is currently in clinical development [223].

\section{Conclusions}

To date, the concept of VaDep is still not widely accepted; there are no formal agreed definitions or diagnostic criteria, the pathomechanisms are not fully understood, the natural history is unknown, and no specific therapy has been confirmed. It is acknowledged that old age depression is a heterogeneous illness with high treatment resistance associated with a number of contributing neurobiological factors, including CVD, neurodegeneration, inflammation, and others, all of which also contribute to its longitudinal prognosis and course $[32,166]$. Elderly people are probably vulnerable to depression, and cardiovascular disease, diabetes mellitus, high cholesterol levels, and other such diseases increase the risk for LLD [32, 46, 61, 86, 224]. Drugs used for cardiovascular disease, such as beta blockers, may also potentially cause depression. Thus, if a stroke victim develops depression, this by itself does not prove a causal relationship. VaDep is frequently presumed to be associated with cognitive decline and an increased risk of subsequent dementia [30]. CVD, deep white matter changes, and other (neurodegenerative) lesions have been hypothesized to contribute to increased risk of dementia in the aged, and a host of neuroimaging and clinicopathological studies have examined the interplay between brain pathologies and LLD. This has resulted in new concepts such as the VaDep hypothesis, but despite multiple studies, the relationship between microstructural and related (biochemical) changes in human brain and LLD remains controversial. Recent studies suggested a relationship between brain levels of high-energy phosphate metabolites and executive function in geriatric depression, which is consistent with predictions of the VaDep hypothesis, but further work is necessary to clarify these effects [225]. Unlike VaDep, the hyperfacilitation of the motor cortex found at baseline in vascular MCI-no dementia patients suggested enhanced glutamatergic neurotransmission that might contribute to the preservation of cognitive functioning in these patients [226]. It seems that diagnosing an elderly person as having VaDep just because imaging studies demonstrate WMHs might be debatable, since the latter are quite common in the elderly anyway, particularly in those with cardiovascular disease. Thus, although there is considerable empiric support for the validity of a VaDep subtype of LLD, fundamental questions remain open, including how the illness is defined, how vascular disease and depression influence each other, why VaDep is not a progressive disorder despite the possible related brain lesions tending to accumulate, and whether executive dysfunction or WMHs and global vascular risk are responsible for poor response to anti-depressive treatment $[28,227]$. While postmortem findings in some elderly suicided persons revealed lacunes, CSVD, WMHs, and AD-related and other pathologies [228], recent autopsy findings in patients fulfilling the diagnostic criteria of VaDep challenged the role of cerebrovascular pathologies as major morphological substrates of depressive symptoms or poorer executive function and memory in the aged. Similarly, neuropathological data suggested that EOD is not associated with an acceleration of age-related cerebral lesions [31]. Of note, selective serotonin reuptake inhibitor treatment is associated with more neurogenesis and angiogenesis in the human hippocampus [229], whereas in the dentate gyrus, there is less neurogenesis and angiogenesis in MDD patients than in controls. Nevertheless, this trend is reversed by selective serotonin reuptake inhibitor treatment [230], suggesting that one of the mechanisms of action of antidepressants could be through re-establishment of the angiogenesis/neurogenesis niche in this region, which is crucial for memory and emotional regulation. In the case of VaDep drugs, sustaining the vasculature could be essential for cell survival, assuming that vascular changes are the first mediators of cellular changes. There is a need for genetic studies related to cerebral pathologies in LLD in order to better grasp its neuronal basis [231]. Such work may benefit not only from examining genetic markers of neurotransmitter or neuronal activity, but also markers related to vascular disease risk [232].

\section{Future directions}

Genomic signature, neurotrophin and transmitter signaling, neuroinflammation, cerebrovascular lesions, hippocampal neurogenesis, age-related neurodegenerative changes, and other hitherto incompletely elucidated factors may all be involved in the complex pathogenetic cascade that precedes depressive and cognitive symptoms in advanced age. A growing body of evidence from neuroimaging, neurophysiology, and peripheral biomarker studies suggests that depression in old age may be associated with abnormalities in vascular-related and other pathobiological processes [163], but the theory of a distinct subtype of depression named VaDep remains to be fully established. 
There are four possible interrelations between cerebrovascular disease and LLD:

(1) Depression is the consequence of vascular disease.

(2) Depression appears independently from vascular disease, but vascular brain disease may stimulate the development and course of depression.

(3) Cerebrovascular pathology and depression may appear without obvious connection as two manifestations of the same genetic predisposition and pathobiological mechanisms.

(4) Depression may cause cardiovascular and/or cerebrovascular disease and there may be a bidirectional relationship between depression and vascular disease, but further studies are needed to clarify the mechanisms involved [46].

Thus, to establish a diagnosis of VaDep, it should be based on adequate criteria, such as:

(1) Evidence of vascular pathology in elderly subjects with or without cognitive impairment.

(2) Absence of previous depressive episodes preceding obvious cerebrovascular disease.

(3) Presence of cerebrovascular risk factors.

(4) Co-incidence of depression with cerebrovascular risk factors.

(5) Clinical symptoms characteristic of VaDep such as executive dysfunction, decrease in processing speed, and lethargy.

(6) Neuroimaging data confirming CVD.

However, the temporal relationship between brain pathology and the development of depressive and related symptoms as well as the etiology of VaDep cannot be established on the basis of postmortem observations alone. Therefore, long-term clinicopathological studies, including premortem and postmortem structural MRI, neuropathology, and in vivo functional MRI studies, are warranted in order to further elucidate the relations between structural brain lesions, related pathobiological lesions, and depression in advanced age. Thus far, functional MRI studies have rarely been performed in VaDep, and the few available PET data should be confirmed. In addition to functional MRI, novel techniques, such as more sophisticated PET and combined biomarker studies, may provide better insight into the pathobiological processes involved in mood and cognitive changes in advanced age in order to definitely establish the existence of VaDep and to promote new interventions for its prevention and treatment. These studies might encourage the inclusion of VaDep in future versions of the DSM, setting standards and consensus-approved clinical criteria for the diagnosis of this disorder.

\section{Abbreviations}

AD: Alzheimer's disease; CSVD: cerebral small vessel disease;

CVD: cerebrovascular disease; DSM: Diagnostic and Statistical Manual; EOD: early-onset depression; LLD: late-life depression; LOD: late-onset depression; MCl: mild cognitive impairment; MDD: major depressive disorder; MRI: magnetic resonance imaging; PET: positron emission tomography; SRI: selective serotonin reuptake inhibitor; VaDep: vascular depression; WMH: white matter hyperintensity

Acknowledgements

The authors thank E. Mitter-Ferstl, PhD, for secretarial work.

\section{Funding}

The study was partially supported by the Society for the Support of Research in Experimental Neurology, Vienna, Austria.

Availability of data and materials

Data sharing not applicable to this article as no datasets were generated or analyzed during the current study.

\section{Authors' contributions}

$K A J$ projected and wrote the article including its revision. $A B, M B, M A B, B S D$, MKJ, LSK, MDM, DCS, KR, KR, WDT, and OT provided substantial contributions to discussion and critical amendments. All authors participated in reviewing and/or editing the manuscript before submission. Special thanks go to Prof. Amos Korczyn for critically reviewing the drafts that were finally revised by KAJ, OT, BSD, SP, LSK, DCS, and WDT. All authors read and approved the final manuscript.

\section{Competing interests}

The authors declare that they have no competing interests.

\section{Author details}

'Department of Psychiatry, University of Pittsburgh Medical Center, Pittsburgh, PA, USA. ${ }^{2}$ Memory Disorders Clinic, Riverside Psychiatric Medical Group, Riverside, CA, USA. ${ }^{3}$ Department of Psychiatry, Columbia University, New York, NY, USA. ${ }^{4}$ Division of Molecular Imaging and Neuropathology, New York State Psychiatric Institute, New York, NY, USA. ${ }^{5}$ Department of Psychiatry, University of Pittsburgh Medical School, Pittsburgh, PA, USA

${ }^{6}$ Department of Psychiatry and Behavioral Sciences, University of Texas Health Science Center at Houston, Houston, TX, USA. ${ }^{7}$ Division of Molecular Imaging and Neuropathology, New York State Psychiatric Institute, Columbia University, New York, NY, USA. ${ }^{8}$ Institute of Clinical Neurobiology,

Alberichgasse 5/13, Vienna A-1150, Austria. ${ }^{9}$ Department of Geriatric

Psychiatry of the St. Petersburg Psychoneurological Research Institute named after V. M. Bekhterev, Medical Faculty of St. Petersburg University, St. Petersburg, Russia. ${ }^{10}$ Clinical Department, Scientific and Practical Center of Psychoneurology named after V. M. Soloviev, St. Petersburg, Russia.

${ }^{11}$ Neurology Clinic, Clinical Center of Serbia, School of Medicine University of Belgrade, Belgrade, Serbia. ${ }^{12}$ University Clinic for Psychiatry and Psychotherapy, Paracelsus Private Medical University, Nuremberg, Germany. ${ }^{13}$ Consultant in Old Age Psychiatry, Cheshire and Wirral Partnership NHS Foundation Trust, Chester, UK. ${ }^{14}$ Faculty for Social Sciences, Technical University of Nuremberg Georg Simon Ohm, Nuremberg, Germany.

${ }^{15}$ Department of Psychiatry, University of Connecticut Health Center, Farmington, CT, USA. ${ }^{16}$ Department of Psychiatry, The Center for Cognitive Medicine, Vanderbilt University Medical Center, Nashville, TN, USA.

${ }^{17}$ Department of Veterans Affairs Medical Center, The Geriatric Research, Education, and Clinical Center (GRECC), Tennessee Valley Healthcare System, Nashville, TN, USA. ${ }^{18}$ Departments of Neurology and Psychiatry, Tel Aviv Medical Center, Tel Aviv, Israel. ${ }^{19}$ Tel Aviv University, Sackler Faculty of Medicine, Tel Aviv, Israel.

Received: 11 June 2016 Accepted: 14 October 2016

Published online: 03 November 2016

\section{References}

1. Steffens DC, Fisher GG, Langa KM, Potter GG, Plassman BL. Prevalence of depression among older Americans: the aging, demographics and memory study. Int Psychogeriatr. 2009;21:879-88. 
2. van Sloten $\Pi$, Sigurdsson $S$, van Buchem MA, Phillips $C L$, Jonsson PV, Ding J, Schram MT, Harris TB, Gudnason V, Launer LJ. Cerebral small vessel disease and association with higher incidence of depressive symptoms in a general elderly population: the Ages-Reykjavik study. Am J Psychiatry. 2015;172:570-8.

3. Lavretsky H, Zheng L, Weiner MW, Mungas D, Reed B, Kramer JH, Jagust W, Chui $\mathrm{H}$, Mack WJ. Association of depressed mood and mortality in older adults with and without cognitive impairment in a prospective naturalistic study. Am J Psychiatry. 2010;167:589-97.

4. Korten NC, Comijs HC, Lamers F, Penninx BW. Early and late onset depression in young and middle aged adults: differential symptomatology, characteristics and risk factors? J Affect Disord. 2012;138:259-67.

5. Mitchell AJ, Subramaniam H. Prognosis of depression in old age compared to middle age: a systematic review of comparative studies. Am J Psychiatry. 2005;162:1588-601.

6. Beekman AT, Geerlings SW, Deeg DJ, Smit JH, Schoevers RS, de Beurs E, Braam AW, Penninx BW, van Tilburg W. The natural history of late-life depression: a 6-year prospective study in the community. Arch Gen Psychiatry. 2002:59:605-11.

7. Aziz R, Steffens DC. What are the causes of late-life depression? Psychiatr Clin North Am. 2013;36:497-516.

8. Sivertsen H, Bjorklof GH, Engedal K, Selbaek G, Helvik AS. Depression and quality of life in older persons: a review. Dement Geriatr Cogn Disord. 2015;40:311-39.

9. Köhler S, Buntinx F, Palmer K, van den Akker M. Depression, vascular factors, and risk of dementia in primary care: a retrospective cohort study. J Am Geriatr Soc. 2015;63:692-8.

10. Almeida OP, Hankey GJ, Yeap BB, Golledge J, Flicker L. Depression as a risk factor for cognitive impairment in later life: the Health in Men cohort study. Int J Geriatr Psychiatry. 2015;31:412-20.

11. Santos M, Gold G, Kovari E, Herrmann FR, Bozikas VP, Bouras C, Giannakopoulos P. Differential impact of lacunes and microvascular lesions on poststroke depression. Stroke. 2009;40:3557-62.

12. Gaupp RE. Depressive states in older age. Med Wochenschrift. 1905;25 1531-7 [In German].

13. Alexopoulos GS, Bruce ML, Silbersweig D, Kalayam B, Stern E. Vascular depression: a new view of late-onset depression. Dialogues Clin Neurosci. 1999;1:68-80.

14. Greenstein AS, Paranthaman R, Burns A, Jackson A, Malik RA, Baldwin RC, Heagerty AM. Cerebrovascular damage in late-life depression is associated with structural and functional abnormalities of subcutaneous small arteries. Hypertension. 2010;56:734-40.

15. Thomas AJ, Perry R, Kalaria RN, Oakley A, McMeekin W, O'Brien JT. Neuropathological evidence for ischemia in the white matter of the dorsolateral prefrontal cortex in late-life depression. Int J Geriatr Psychiatry. 2003;18:7-13.

16. Alexopoulos GS, Meyers BS, Young RC, Campbell S, Silbersweig D, Charlson M. 'Vascular depression' hypothesis. Arch Gen Psychiatry. 1997;54:915-22.

17. Park JH, Lee SB, Lee JJ, Yoon JC, Han JW, Kim TH, Jeong HG, Newhouse PA, Taylor WD, Kim JH, et al. Epidemiology of MRI-defined vascular depression: a longitudinal, community-based study in Korean elders. J Affect Disord. 2015:180:200-6

18. Krishnan KR, Hays JC, Blazer DG. MRI-defined vascular depression. Am J Psychiatry. 1997;154:497-501.

19. Krishnan KR, Taylor WD, McQuoid DR, MacFall JR, Payne ME, Provenzale JM, Steffens DC. Clinical characteristics of magnetic resonance imaging-defined subcortical ischemic depression. Biol Psychiatry. 2004;55:390-7.

20. Pimontel MA, Reinlieb ME, Johnert LC, Garcon E, Sneed JR, Roose SP. The external validity of MRI-defined vascular depression. Int J Geriatr Psychiatry. 2013:28:1189-96

21. Kales HC, Maixner DF, Mellow AM. Cerebrovascular disease and late-life depression. Am J Geriatr Psychiatry. 2005;13:88-98.

22. Turk BR, Gschwandtner ME, Mauerhofer M, Loffler-Stastka H. Can we clinically recognize a vascular depression? The role of personality in an expanded threshold model. Medicine (Baltimore). 2015;94:e743.

23. Licht-Strunk E, Bremmer MA, van Marwijk HW, Deeg DJ, Hoogendijk WJ, de Haan M, van Tilburg W, Beekman AT. Depression in older persons with versus without vascular disease in the open population: similar depressive symptom patterns, more disability. J Affect Disord. 2004;83:155-60.

24. Naarding P, Tiemeier H, Breteler MM, Schoevers RA, Jonker C, Koudstaal PJ, Beekman AT. Clinically defined vascular depression in the general population. Psychol Med. 2007;37:383-92.

25. Butters MA, Young JB, Lopez O, Aizenstein HJ, Mulsant BH, Reynolds 3rd CF, DeKosky ST, Becker JT. Pathways linking late-life depression to persistent cognitive impairment and dementia. Dialogues Clin Neurosci. 2008;10(3):345-57.
26. Thuile J, Even C, Guelfi JD. Validity of vascular depression as a specific diagnostic: a review. Encéphale. 2007;33:39-48.

27. Rainer MK, Mucke HA, Zehetmayer S, Krampla W, Kuselbauer T, Weissgram S, Jungwirth S, Tragl KH, Fischer P. Data from the VITA Study do not support the concept of vascular depression. Am J Geriatr Psychiatry. 2006;14:531-7.

28. Sneed JR, Culang-Reinlieb ME. The vascular depression hypothesis: an update. Am J Geriatr Psychiatry. 2011;19:99-103.

29. Aizenstein HJ, Khalaf A, Walker SE, Andreescu C. Magnetic resonance imaging predictors of treatment response in late-life depression. J Geriatr Psychiatry Neurol. 2014;27:24-32.

30. Diniz BS, Butters MA, Albert SM, Dew MA, Reynolds 3rd CF. Late-life depression and risk of vascular dementia and Alzheimer's disease: systematic review and meta-analysis of community-based cohort studies. Br J Psychiatry. 2013;202:329-35.

31. Jellinger KA. Organic bases of late-life depression: a critical update. J Neural Transm. 2013:120:1109-25.

32. Naismith SL, Norrie LM, Mowszowski L, Hickie IB. The neurobiology of depression in later-life: clinical, neuropsychological, neuroimaging and pathophysiological features. Prog Neurobiol. 2012;98:99-143.

33. Yasuno F, Kazui H, Morita N, Kajimoto K, Ihara M, Taguchi A, Yamamoto A, Matsuoka K, Kosaka J, Kudo T, et al. High amyloid-beta deposition related to depressive symptoms in older individuals with normal cognition: a pilot study. Int J Geriatr Psychiatry. 2016;31(8):920-8.

34. Mahgoub N, Alexopoulos GS. Amyloid hypothesis: is there a role for antiamyloid treatment in late-life depression? Am J Geriatr Psychiatry. 2016;24:239-47.

35. Culang-Reinlieb ME, Johnert LC, Brickman AM, Steffens DC, Garcon E, Sneed JR. MRI-defined vascular depression: a review of the construct. Int J Geriatr Psychiatry. 2011;26:1101-8.

36. Disabato BM, Sheline YI. Biological basis of late life depression. Curr Psychiatry Rep. 2012;14:273-9.

37. Taylor WD, Aizenstein HJ, Alexopoulos GS. The vascular depression hypothesis: mechanisms linking vascular disease with depression. Mol Psychiatry. 2013;18:963-74.

38. Serafini G, Amore M, Rihmer Z. Microstructural brain abnormalities, affective temperaments, and suicidal behavior in patients with major depression. Neuroimmunol Neuroinflammation. 2015;2:200-14.

39. Agudelo C, Aizenstein HJ, Karp JF, Reynolds 3rd CF. Applications of magnetic resonance imaging for treatment-resistant late-life depression. Dialogues Clin Neurosci. 2015;17:151-69.

40. Hybels CF, Pieper CF, Payne ME, Steffens DC. Late-life depression modifies the association between cerebral white matter hyperintensities and functional decline among older adults. Am J Geriatr Psychiatry. 2016;24(1):42-9.

41. Naarding P, Noorthoorn EO, Burm TL, van der Mast RC, Beekman AT, Comijs HC. Cerebrovascular involvement and clinical presentation of late-life depression findings from the NESDO study. Aging Ment Health. 2016;20(10):1099-106.

42. Jellinger KA. The enigma of vascular depression. Austin Alzh Parkinson Dis. 2016;3:1026.

43. Paranthaman R, Burns AS, Cruickshank JK, Jackson A, Scott ML, Baldwin RC Age at onset and vascular pathology in late-life depression. Am J Geriatr Psychiatry. 2012;20:524-32.

44. Concerto C, Lanza G, Cantone M, Pennisi M, Giordano D, Spampinato C Ricceri R, Pennisi G, Aguglia E, Bella R. Different patterns of cortical excitability in major depression and vascular depression: a transcranial magnetic stimulation study. BMC Psychiatry. 2013;13:300.

45. Pan A, Keum N, Okereke OI, Sun Q, Kivimaki M, Rubin RR, Hu FB. Bidirectional association between depression and metabolic syndrome: a systematic review and meta-analysis of epidemiological studies. Diabetes Care. 2012;35:1171-80

46. Thomas AJ, Kalaria RN, O'Brien JT. Depression and vascular disease: what is the relationship? J Affect Disord. 2004;79:81-95.

47. Sexton CE, McDermott L, Kalu UG, Herrmann LL, Bradley KM, Allan CL, Le Masurier M, Mackay CE, Ebmeier KP. Exploring the pattern and neural correlates of neuropsychological impairment in late-life depression. Psychol Med. 2012;42:1195-202.

48. Vu NQ, Aizenstein HJ. Depression in the elderly: brain correlates, neuropsychological findings, and role of vascular lesion load. Curr Opin Neurol. 2013;26:656-61.

49. Byers AL, Yaffe K. Depression and risk of developing dementia. Nat Rev Neurol. 2011;7:323-31.

50. Alexopoulos GS. Depression in the elderly. Lancet. 2005;365:1961-70.

51. Thomas P, Hazif Thomas C, Billon R, Peix R, Faugeron P, Clement JP. Depression and frontal dysfunction: risks for the elderly? Encéphale. 2009;35:361-9. 
52. Köhler S, Verhey FR. Cognitive deficits in late-life depression. Tijdschr Psychiatr. 2011;53:601-7.

53. Zuidersma M, Izaks GJ, Naarding P, Comijs HC, Oude Voshaar RC. Vascular burden and cognitive function in late-life depression. Am J Geriatr Psychiatry. 2015;23: 514-24.

54. Grool AM, Gerritsen L, Zuithoff NP, Mali WP, van der Graaf Y, Geerlings MI. Lacunar infarcts in deep white matter are associated with higher and more fluctuating depressive symptoms during three years follow-up. Biol Psychiatry. 2013;73:169-76.

55. Chang KJ, Hong CH, Kim SH, Lee KS, Roh HW, Kang DR, Choi SH, Kim SY, Na DL, Seo SW, et al. MRI-defined versus clinically-defined vascular depression; comparison of prediction of functional disability in the elderly. Arch Gerontol Geriatr. 2016;66:7-12.

56. Potter GG, McQuoid DR, Steffens DC, Welsh-Bohmer KA, Krishnan KR. Neuropsychological correlates of magnetic resonance imaging-defined subcortical ischemic depression. Int J Geriatr Psychiatry. 2009;24:219-25.

57. Starkstein SE, Fedoroff JP, Price TR, Leiguarda R, Robinson RG. Apathy following cerebrovascular lesions. Stroke. 1993;24:1625-30.

58. Bergman Levy T, Barak Y, Sigler M, Aizenberg D. Suicide attempts and burden of physical illness among depressed elderly inpatients. Arch Gerontol Geriatr. 2011;52:115-7.

59. Reinlieb ME, Persaud A, Singh D, Garcon E, Rutherford BR, Pelton GH, Devanand DP, Roose SP, Sneed JR. Vascular depression: overrepresented among African Americans? Int J Geriatr Psychiatry. 2014;29:470-7.

60. McDermott MM, Guralnik JM, Tian L, Kibbe MR, Ferrucci L, Zhao L, Liu K, Liao Y, Gao Y, Criqui MH. Incidence and prognostic significance of depressive symptoms in peripheral artery disease. J Am Heart Assoc. 2016;5(3), e002959.

61. Daskalopoulou M, George J, Walters K, Osborn DP, Batty GD, Stogiannis D, Rapsomaniki E, Pujades-Rodriguez M, Denaxas S, Udumyan R, et al. Depression as a risk factor for the initial presentation of twelve cardiac, cerebrovascular, and peripheral arterial diseases: data linkage study of 1.9 million women and men. PLoS One. 2016;11, e0153838.

62. Pequignot R, Dufouil C, Prugger C, Peres K, Artero S, Tzourio C, Empana JP. High level of depressive symptoms at repeated study visits and risk of coronary heart disease and stroke over 10 years in older adults: The Three-City Study. J Am Geriatr Soc. 2016;64:118-25.

63. D'Audiffret AC, Frisbee SJ, Stapleton PA, Goodwill AG, Isingrini E, Frisbee JC. Depressive behavior and vascular dysfunction: a link between clinical depression and vascular disease? J Appl Physiol (1985). 2010;108:1041-51.

64. Bouzinova EV, Wiborg O, Aalkjaer C, Matchkov W. Role of peripheral vascular resistance for the association between major depression and cardiovascular disease. J Cardiovasc Pharmacol. 2015;65:299-307.

65. Peters R, Pinto E, Beckett N, Swift C, Potter J, McCormack T, Nunes M, Grimley-Evans J, Fletcher A, Bulpitt C. Association of depression with subsequent mortality, cardiovascular morbidity and incident dementia in people aged 80 and over and suffering from hypertension. Data from the Hypertension in the Very Elderly Trial (HYVET). Age Ageing. 2010;39:439-45.

66. Kozela M, Bobak M, Besala A, Micek A, Kubinova R, Malyutina S, Denisova D, Richards M, Pikhart $\mathrm{H}$, Peasey A, et al. The association of depressive symptoms with cardiovascular and all-cause mortality in Central and Eastern Europe: prospective results of the HAPIEE study. Eur J Prev Cardiol. 2016. doi:10.1177/2047487316649493.

67. Sun WJ, Xu L, Chan WM, Lam TH, Schooling CM. Are depressive symptoms associated with cardiovascular mortality among older Chinese: a cohort study of 64,000 people in Hong Kong? Am J Geriatr Psychiatry. 2013;21: 1107-15.

68. Choi NG, Kim J, Marti CN, Chen GJ. Late-life depression and cardiovascular disease burden: examination of reciprocal relationship. Am J Geriatr Psychiatry. 2014;22:1522-9.

69. Capistrant BD, Gilsanz P, Moon JR, Kosheleva A, Patton KK, Glymour MM Does the association between depressive symptoms and cardiovascular mortality risk vary by race? Evidence from the Health and Retirement Study. Ethn Dis. 2013;23:155-60.

70. Van der Kooy K, van Hout H, Marwijk H, Marten H, Stehouwer C, Beekman A. Depression and the risk for cardiovascular diseases: systematic review and meta analysis. Int J Geriatr Psychiatry. 2007;22:613-26.

71. Lee SR, Choi B, Paul S, Seo JH, Back DB, Han JS, Choi DH, Kwon KJ, Shin CY, Lee J, et al. Depressive-like behaviors in a rat model of chronic cerebral hypoperfusion. Transl Stroke Res. 2015;6:207-14.

72. Jackson CA, Mishra GD. Depression and risk of stroke in midaged women: a prospective longitudinal study. Stroke. 2013;44:1555-60.
73. Cherbuin N, Kim S, Anstey KJ. Dementia risk estimates associated with measures of depression: a systematic review and meta-analysis. BMJ Open. 2015;5, e008853.

74. Kim S, Woo SY, Kang HS, Lim SW, Choi SH, Myung W, Jeong JH, Lee Y, Hong $\mathrm{CH}$, Kim JH, et al. Factors related to prevalence, persistence, and incidence of depressive symptoms in mild cognitive impairment: vascular depression construct. Int J Geriatr Psychiatry. 2015;31:818-26.

75. Wu KY, Liu CY, Chen CS, Chen CH, Hsiao IT, Hsieh CJ, Lee CP, Yen TC, Lin KJ. Betaamyloid deposition and cognitive function in patients with major depressive disorder with different subtypes of mild cognitive impairment: (18)F-florbetapir (AV-45/Amyvid) PET study. Eur J Nucl Med Mol Imaging. 2016;43:1067-76.

76. Mourao RJ, Mansur G, Malloy-Diniz LF, Castro Costa E, Diniz BS. Depressive symptoms increase the risk of progression to dementia in subjects with mild cognitive impairment: systematic review and meta-analysis. Int J Geriatr Psychiatry. 2016;31:905-11.

77. Kaup AR, Byers AL, Falvey C, Simonsick EM, Satterfield S, Ayonayon HN, Smagula SF, Rubin SM, Yaffe K. Trajectories of depressive symptoms in older adults and risk of dementia. JAMA Psychiat. 2016;73:525-31.

78. Mirza SS, Wolters FJ, Swanson SA, Koudstaal PJ, Hofman A, Tiemeier H, Ikram MA. 10-year trajectories of depressive symptoms and risk of dementia: a population-based study. Lancet Psychiatry. 2016;3:628-35.

79. Ravaglia G, Forti P, Lucicesare A, Rietti E, Pisacane N, Mariani E, Dalmonte E. Prevalent depressive symptoms as a risk factor for conversion to mild cognitive impairment in an elderly Italian cohort. Am J Geriatr Psychiatry. 2008;16:834-43.

80. Godin O, Dufouil C, Ritchie K, Dartigues JF, Tzourio C, Peres K, Artero S, Alperovitch A. Depressive symptoms, major depressive episode and cognition in the elderly: the three-city study. Neuroepidemiology. 2007;28:101-8.

81. Barnes DE, Alexopoulos GS, Lopez OL, Williamson JD, Yaffe K. Depressive symptoms, vascular disease, and mild cognitive impairment: findings from the Cardiovascular Health Study. Arch Gen Psychiatry. 2006;63:273-9.

82. Zuidersma M, Comijs HC, Naarding P, Oude Voshaar RC. Cognitive performance in depressed older persons: the impact of vascular burden and remission. A two-year follow-up study. Int J Geriatr Psychiatry. 2016;31(9):1029-39.

83. Pasi M, Poggesi A, Salvadori E, Diciotti S, Ciolli L, Del Bene A, Marini S, Nannucci S, Pescini F, Valenti $R$, et al. White matter microstructural damage and depressive symptoms in patients with mild cognitive impairment and cerebral small vessel disease: the VMCl-Tuscany Study. Int J Geriatr Psychiatry. 2016;31(6):611-8. doi:10.1002/gps.4368.

84. Panza F, D'Introno A, Colacicco AM, Capurso C, Del Parigi A, Caselli RJ, Todarello O, Pellicani V, Santamato A, Scapicchio P, et al. Depressive symptoms, vascular risk factors and mild cognitive impairment. The Italian longitudinal study on aging. Dement Geriatr Cogn Disord. 2008;25:336-46.

85. Alexopoulos GS. Vascular disease, depression, and dementia. J Am Geriatr Soc. 2003:51:1178-80.

86. Lin WC, Hu LY, Tsai SJ, Yang AC, Shen CC. Depression and the risk of vascular dementia: a population-based retrospective cohort study. Int J Geriatr Psychiatry. 2016. doi:10.1002/gps.4493.

87. van den Kommer TN, Comijs HC, Aartsen MJ, Huisman M, Deeg DJ, Beekman AT. Depression and cognition: how do they interrelate in old age? Am J Geriatr Psychiatry. 2013;21:398-410.

88. Park JH, Lee SB, Lee TJ, Lee DY, Jhoo JH, Youn JC, Choo IH, Choi EA, Jeong JW, Choe JY, et al. Depression in vascular dementia is quantitatively and qualitatively different from depression in Alzheimer's disease. Dement Geriatr Cogn Disord. 2007;23:67-73.

89. Wilson RS, Capuano AW, Boyle PA, Hoganson GM, Hizel LP, Shah RC, Nag S, Schneider JA, Arnold SE, Bennett DA. Clinical-pathologic study of depressive symptoms and cognitive decline in old age. Neurology. 2014;83:702-9.

90. Wilson RS, Boyle PA, Capuano AW, Shah RC, Hoganson GM, Nag S, Bennett DA. Late-life depression is not associated with dementia-related pathology. Neuropsychology. 2016;30(2):135-42. doi:10.1037/neu0000223.

91. McCutcheon ST, Han D, Troncoso J, Koliatsos VE, Albert M, Lyketsos CG, Leoutsakos JS. Clinicopathological correlates of depression in early Alzheimer's disease in the NACC. Int J Geriatr Psychiatry. 2016. Ahead of print. doi:10.1002/gps.4435.

92. De Roeck E, Ponjaert-Kristoffersen I, Bosmans M, De Deyn PP, Engelborghs $\mathrm{S}$, Dierckx E. Are depressive symptoms in mild cognitive impairment predictive of conversion to dementia? Int Psychogeriatr. 2016;28(6):921-8.

93. Osorio RS, Gumb T, Pomara N. Soluble amyloid-beta levels and late-life depression. Curr Pharm Des. 2014;20:2547-54.

94. Sexton CE, Mackay CE, Ebmeier KP. A systematic review and meta-analysis of magnetic resonance imaging studies in late-life depression. Am J Geriatr Psychiatry. 2013;21:184-95. 
95. Sneed JR, Rindskopf D, Steffens DC, Krishnan KR, Roose SP. The vascular depression subtype: evidence of internal validity. Biol Psychiatry. 2008;64:491-7.

96. Colloby SJ, Firbank MJ, Thomas AJ, Vasudev A, Parry SW, O'Brien JT. White matter changes in late-life depression: a diffusion tensor imaging study. J Affect Disord. 2011;135:216-20.

97. Firbank MJ, O'Brien JT, Pakrasi S, Pantoni L, Simoni M, Erkinjuntti T, Wallin A, Wahlund LO, van Straaten I, Inzitari D. White matter hyperintensities and depression-preliminary results from the LADIS study. Int J Geriatr Psychiatry. 2005;20:674-9.

98. Herrmann LL, Le Masurier M, Ebmeier KP. White matter hyperintensities in late life depression: a systematic review. J Neurol Neurosurg Psychiatry. 2008;79:619-24.

99. Shimony JS, Sheline YI, D'Angelo G, Epstein AA, Benzinger TL, Mintun MA, McKinstry RC, Snyder AZ. Diffuse microstructural abnormalities of normalappearing white matter in late life depression: a diffusion tensor imaging study. Biol Psychiatry. 2009;66:245-52.

100. Steffens DC, Taylor WD, Denny KL, Bergman SR, Wang L. Structural integrity of the uncinate fasciculus and resting state functional connectivity of the ventral prefrontal cortex in late life depression. PLoS One. 2011;6, e22697.

101. Wang $L$, Leonards CO, Sterzer P, Ebinger M. White matter lesions and depression: a systematic review and meta-analysis. J Psychiatr Res. 2014;56:56-64.

102. Taylor WD, MacFall JR, Payne ME, McQuoid DR, Steffens DC, Provenzale JM, Krishnan RR. Greater MRI lesion volumes in elderly depressed subjects than in control subjects. Psychiatry Res. 2005;139:1-7.

103. Dalby RB, Chakravarty MM, Ahdidan J, Sorensen L, Frandsen J, Jonsdottir KY, Tehrani E, Rosenberg R, Ostergaard L, Videbech P. Localization of whitematter lesions and effect of vascular risk factors in late-onset major depression. Psychol Med. 2010;40:1389-99.

104. Sheline YI, Price JL, Vaishnavi SN, Mintun MA, Barch DM, Epstein AA, Wilkins $\mathrm{CH}$, Snyder AZ, Couture L, Schechtman K, McKinstry RC. Regional white matter hyperintensity burden in automated segmentation distinguishes late-life depressed subjects from comparison subjects matched for vascular risk factors. Am J Psychiatry. 2008;165:524-32.

105. Taylor WD, Zhao Z, Ashley-Koch A, Payne ME, Steffens DC, Krishnan RR, Hauser E, MacFall JR. Fiber tract-specific white matter lesion severity findings in late-life depression and by AGTR1 A1166C genotype. Hum Brain Mapp. 2013;34:295-303.

106. Wen MC, Steffens DC, Chen MK, Zainal NH. Diffusion tensor imaging studies in late-life depression: systematic review and meta-analysis. Int J Geriatr Psychiatry. 2014;29:1173-84.

107. Krishnan MS, O'Brien JT, Firbank MJ, Pantoni L, Carlucci G, Erkinjuntti T, Wallin A, Wahlund LO, Scheltens P, van Straaten EC, Inzitari D. Relationship between periventricular and deep white matter lesions and depressive symptoms in older people. The LADIS Study. Int J Geriatr Psychiatry. 2006;21:983-9.

108. Delano-Wood L, Abeles N, Sacco JM, Wierenga CE, Horne NR, Bozoki A. Regional white matter pathology in mild cognitive impairment: differential influence of lesion type on neuropsychological functioning. Stroke. 2008;39:794-9.

109. O'Brien JT, Firbank MJ, Krishnan MS, van Straaten EC, van der Flier WM, Petrovic K, Pantoni L, Simoni M, Erkinjuntti T, Wallin A, et al. White matter hyperintensities rather than lacunar infarcts are associated with depressive symptoms in older people: the LADIS study. Am J Geriatr Psychiatry. 2006;14:834-41.

110. Godin O, Dufouil C, Maillard P, Delcroix N, Mazoyer B, Crivello F, Alperovitch A, Tzourio C. White matter lesions as a predictor of depression in the elderly: the 3C-Dijon study. Biol Psychiatry. 2008;63:663-9.

111. Yao H, Takashima Y, Araki Y, Uchino A, Yuzuriha T, Hashimoto M. Leisuretime physical inactivity associated with vascular depression or apathy in community-dwelling elderly subjects: the Sefuri study. J Stroke Cerebrovasc Dis. 2015;24:2625-31

112. Firbank MJ, Teodorczuk A, van der Flier WM, Gouw AA, Wallin A, Erkinjuntti T, Inzitari D, Wahlund LO, Pantoni L, Poggesi A, et al. Relationship between progression of brain white matter changes and late-life depression: 3-year results from the LADIS study. Br J Psychiatry. 2012;201:40-5.

113. Teodorczuk A, O'Brien JT, Firbank MJ, Pantoni L, Poggesi A, Erkinjuntti T, Wallin A, Wahlund LO, Gouw A, Waldemar G, et al. White matter changes and late-life depressive symptoms: longitudinal study. Br J Psychiatry. 2007;191:212-7.

114. Teodorczuk A, Firbank MJ, Pantoni L, Poggesi A, Erkinjuntti T, Wallin A, Wahlund LO, Scheltens P, Waldemar G, Schrotter G, et al. Relationship between baseline white-matter changes and development of late-life depressive symptoms: 3-year results from the LADIS study. Psychol Med. 2010;40:603-10.

115. Qiu WQ, Himali JJ, Wolf PA, DeCarli DC, Beiser A, Au R. Effects of white matter integrity and brain volumes on late life depression in the Framingham Heart Study. Int J Geriatr Psychiatry. 2016. doi:10.1002/gps.4469.
116. Takahashi K, Oshima A, Ida I, Kumano H, Yuuki N, Fukuda M, Amanuma M, Endo K, Mikuni M. Relationship between age at onset and magnetic resonance image-defined hyperintensities in mood disorders. J Psychiatr Res. 2008:42:443-50.

117. Allan CL, Sexton CE, Kalu UG, McDermott LM, Kivimaki M, Singh-Manoux A, Mackay CE, Ebmeier KP. Does the Framingham Stroke Risk Profile predict white-matter changes in late-life depression? Int Psychogeriatr. 2012;24(4): 524-31.

118. Mast BT, Miles T, Penninx BW, Yaffe K, Rosano C, Satterfield S, Ayonayon HN, Harris T, Simonsick EM. Vascular disease and future risk of depressive symptomatology in older adults: findings from the Health, Aging, and Body Composition study. Biol Psychiatry. 2008;64:320-6.

119. Sheline Yl, Pieper CF, Barch DM, Welsh-Bohmer K, McKinstry RC, MacFall JR, D'Angelo G, Garcia KS, Gersing K, Wilkins C, et al. Support for the vascular depression hypothesis in late-life depression: results of a 2-site, prospective, antidepressant treatment trial. Arch Gen Psychiatry. 2010;67:277-85.

120. van der Heijden FM, Zeebregts CJ, Reijnen MM. Does extracranial arterial pathology play a role in late-onset psychiatric disorders? Cogn Behav Neurol. 2010;23:147-51.

121. Prins ND, Scheltens $P$. White matter hyperintensities, cognitive impairment and dementia: an update. Nat Rev Neurol. 2015;11:157-65.

122. Nebes RD, Reynolds 3rd CF, Boada F, Meltzer CC, Fukui MB, Saxton J, Halligan EM, DeKosky ST. Longitudinal increase in the volume of white matter hyperintensities in late-onset depression. Int J Geriatr Psychiatry. 2002:17:526-30.

123. Taylor WD, Steffens DC, MacFall JR, McQuoid DR, Payne ME, Provenzale JM, Krishnan KR. White matter hyperintensity progression and late-life depression outcomes. Arch Gen Psychiatry. 2003;60:1090-6.

124. Lee JJ, Lee EY, Lee SB, Park JH, Kim TH, Jeong HG, Kim JH, Han JW, Kim KW. Impact of white matter lesions on depression in the patients with Alzheimer's disease. Psychiatry Investig. 2015;12:516-22.

125. Olazarán J, García-Polo P, García-Frank D, Quirós A, Hernández-Tamames JA, Acedo C, Álvarez-Linera J, Frank A. Structural correlates of depressive symptoms in prodromal Alzheimer's disease. Br J Med Med Res. 2016;14:1-10.

126. Canu E, Kostic M, Agosta F, Munjiza A, Ferraro PM, Pesic D, Copetti M, Peljto A, Lecic Tosevski D, Filippi M. Brain structural abnormalities in patients with major depression with or without generalized anxiety disorder comorbidity. J Neurol. 2015;262:1255-65.

127. Gudayol-Ferre E, Pero-Cebollero M, Gonzalez-Garrido AA, Guardia-Olmos J. Changes in brain connectivity related to the treatment of depression measured through fMRl: a systematic review. Front Hum Neurosci. 2015;9:582.

128. Disabato BM, Morris C, Hranilovich J, D'Angelo GM, Zhou G, Wu N, Doraiswamy PM, Sheline YI. Comparison of brain structural variables, neuropsychological factors, and treatment outcome in early-onset versus late-onset late-life depression. Am J Geriatr Psychiatry. 2014;22:1039-46.

129. Ribeiz SR, Duran F, Oliveira MC, Bezerra D, Castro CC, Steffens DC, Busatto Filho G, Bottino CM. Structural brain changes as biomarkers and outcome predictors in patients with late-life depression: a cross-sectional and prospective study. PLoS One. 2013;8, e80049.

130. Du M, Liu J, Chen Z, Huang X, Li J, Kuang W, Yang Y, Zhang W, Zhou D, Bi $F$, et al. Brain grey matter volume alterations in late-life depression. J Psychiatry Neurosci. 2014;39:397-406.

131. Jayaweera HK, Hickie IB, Duffy SL, Hermens DF, Mowszowski L, Diamond K, Terpening Z, Paradise M, Lewis SJ, Lagopoulos J, Naismith SL. Mild cognitive impairment subtypes in older people with depressive symptoms: relationship with clinical variables and hippocampal change. J Geriatr Psychiatry Neurol. 2015;28:174-83.

132. Harada K, Matsuo K, Nakashima M, Hobara T, Higuchi N, Higuchi F, Nakano M, Otsuki K, Shibata T, Watanuki T, et al. Disrupted orbitomedial prefrontal limbic network in individuals with later-life depression. J Affect Disord. 2016;204:112-9.

133. Tudorascu DL, Rosano C, Venkatraman VK, MacCloud RL, Harris T, Yaffe K, Newman AB, Aizenstein HJ. Multimodal MRI markers support a model of small vessel ischemia for depressive symptoms in very old adults. Psychiatry Res. 2014;224:73-80.

134. Gudmundsson P, Olesen PJ, Simoni M, Pantoni L, Ostling S, Kern S, Guo X, Skoog I. White matter lesions and temporal lobe atrophy related to incidence of both dementia and major depression in 70-year-olds followed over 10 years. Eur J Neurol. 2015;22:781-8. e49-50.

135. Schmaal L, Veltman DJ, van Erp TG, Samann PG, Frodl T, Jahanshad N, Loehrer E, Tiemeier H, Hofman A, Niessen WJ, et al. Subcortical brain 
alterations in major depressive disorder: findings from the ENIGMA Major Depressive Disorder working group. Mol Psychiatry. 2016;21(6):806-12.

136. Bijanki KR, Matsui JT, Mayberg HS, Magnotta VA, Arndt S, Johnson HJ, Nopoulos P, Paradiso S, McCormick LM, Fiedorowicz JG, et al. Depressive symptoms related to low fractional anisotropy of white matter underlying the right ventral anterior cingulate in older adults with atherosclerotic vascular disease. Front Hum Neurosci. 2015;9:408.

137. Newson RS, Hek K, Luijendijk HJ, Hofman A, Witteman JC, Tiemeier H. Atherosclerosis and incident depression in late life. Arch Gen Psychiatry. 2010;67:1144-51

138. Paranthaman R, Greenstein AS, Burns AS, Cruickshank JK, Heagerty AM, Jackson A, Malik RA, Scott ML, Baldwin RC. Vascular function in older adults with depressive disorder. Biol Psychiatry. 2010;68:133-9.

139. Brookes RL, Herbert V, Lawrence AJ, Morris RG, Markus HS. Depression in small-vessel disease relates to white matter ultrastructural damage, not disability. Neurology. 2014;83:1417-23.

140. Wu M, Andreescu C, Butters MA, Tamburo R, Reynolds 3rd CF, Aizenstein H. Default-mode network connectivity and white matter burden in late-life depression. Psychiatry Res. 2011;194:39-46.

141. Venkatraman VK, Aizenstein H, Guralnik J, Newman AB, Glynn NW, Taylor C, Studenski S, Launer L, Pahor M, Williamson J, Rosano C. Executive control function, brain activation and white matter hyperintensities in older adults. Neuroimage. 2010;49:3436-42.

142. Tadayonnejad R, Ajilore O. Brain network dysfunction in late-life depression: a literature review. J Geriatr Psychiatry Neurol. 2014;27:5-12.

143. Dutta A, McKie S, Deakin JF. Resting state networks in major depressive disorder. Psychiatry Res. 2014;224:139-51.

144. Santos M, Kovari E, Hof PR, Gold G, Bouras C, Giannakopoulos P. The impact of vascular burden on late-life depression. Brain Res Rev. 2009;62:19-32.

145. Wu RH, Li Q, Tan Y, Liu XY, Huang J. Depression in silent lacunar infarction: a cross-sectional study of its association with location of silent lacunar infarction and vascular risk factors. Neurol Sci. 2014;35:1553-9.

146. Feng C, Fang M, Xu Y, Hua T, Liu XY. Microbleeds in late-life depression: comparison of early- and late-onset depression. Biomed Res Int. 2014; 2014:682092.

147. Direk N, Perez HS, Akoudad S, Verhaaren BF, Niessen WJ, Hofman A, Vernooij MW, Ikram MA, Tiemeier H. Markers of cerebral small vessel disease and severity of depression in the general population. Psychiatry Res. 2016;253:1-6.

148. Colloby SJ, Firbank MJ, He J, Thomas AJ, Vasudev A, Parry SW, O'Brien JT. Regional cerebral blood flow in late-life depression: arterial spin labelling magnetic resonance study. Br J Psychiatry. 2012;200:150-5.

149. Direk N, Koudstaal PJ, Hofman A, Ikram MA, Hoogendijk WJ, Tiemeier H. Cerebral hemodynamics and incident depression: the Rotterdam Study. Biol Psychiatry. 2012;72:318-23.

150. Pavlovic AM, Pekmezovic T, Zidverc Trajkovic J, Svabic Medjedovic T, Veselinovic N, Radojicic A, Mijajlovic M, Tomic G, Jovanovic Z, Norton M, Sternic N. Baseline characteristic of patients presenting with lacunar stroke and cerebral small vessel disease may predict future development of depression. Int J Geriatr Psychiatry. 2015;31:58-65.

151. Kozdag G, Yalug I, Inan N, Ertas G, Selekler M, Kutlu H, Kutlu A, Emre E, Cetin M, Ural D. Major depressive disorder in chronic heart failure patients: Does silent cerebral infarction cause major depressive disorder in this patient population? Turk Kardiyol Dern Ars. 2015;43:505-12.

152. Hickie I, Simons L, Naismith S, Simons J, McCallum J, Pearson K. Vascular risk to late-life depression: evidence from a longitudinal community study. Aust N Z J Psychiatry. 2003;37:62-5.

153. Grool AM, van der Graaf Y, Mali WP, Geerlings MI. Location of cerebrovascular and degenerative changes, depressive symptoms and cognitive functioning in later life: the SMART-Medea study. J Neurol Neurosurg Psychiatry. 2011;82:1093-100.

154. Grool AM, van der Graaf Y, Mali WP, Witkamp TD, Vincken KL, Geerlings MI. Location and progression of cerebral small-vessel disease and atrophy, and depressive symptom profiles: the Second Manifestations of ARTerial disease (SMART)-Medea study. Psychol Med. 2012;42:359-70.

155. Hollocks MJ, Lawrence AJ, Brookes RL, Barrick TR, Morris RG, Husain M, Markus HS. Differential relationships between apathy and depression with white matter microstructural changes and functional outcomes. Brain. 2015;138:3803-15.

156. Smagula SF, Butters MA, Anderson SJ, Lenze EJ, Dew MA, Mulsant BH, Lotrich FE, Aizenstein H, Reynolds 3rd CF. Antidepressant response trajectories and associated clinical prognostic factors among older adults. JAMA Psychiat. 2015;72:1021-8.
157. Diniz BS, Teixeira AL, Talib L, Gattaz WF, Forlenza OV. Interleukin-1 beta serum levels is increased in antidepressant-free elderly depressed patients. Am J Geriatr Psychiatry. 2010;18:172-6.

158. Diniz BS, Teixeira AL, Miranda AS, Talib LL, Gattaz WF, Forlenza OV. Circulating glial-derived neurotrophic factor is reduced in late-life depression. J Psychiatr Res. 2012:46:135-9.

159. Diniz BS, Teixeira AL, Campos AC, Miranda AS, Rocha NP, Talib LL, Gattaz WF, Forlenza OV. Reduced serum levels of adiponectin in elderly patients with major depression. J Psychiatr Res. 2012;46:1081-5.

160. Diniz BS, Teixeira AL, Talib LL, Mendonca VA, Gattaz WF, Forlenza OV. Increased soluble TNF receptor 2 in antidepressant-free patients with latelife depression. J Psychiatr Res. 2010;44:917-20.

161. Diniz BS, Teixeira AL, Talib LL, Mendonca VA, Gattaz WF, Forlenza OV. Serum brain-derived neurotrophic factor level is reduced in antidepressant-free patients with late-life depression. World J Biol Psychiatry. 2010;11:550-5.

162. Torres-Platas SG, Nagy C, Wakid M, Turecki G, Mechawar N. Glial fibrillary acidic protein is differentially expressed across cortical and subcortical regions in healthy brains and downregulated in the thalamus and caudate nucleus of depressed suicides. Mol Psychiatry. 2016;21:509-15.

163. Diniz BS, Sibille E, Ding Y, Tseng G, Aizenstein HJ, Lotrich F, Becker JT, Lopez OL, Lotze MT, Klunk WE, et al. Plasma biosignature and brain pathology related to persistent cognitive impairment in late-life depression. Mol Psychiatry. 2015;20:594-601.

164. Carvalho AF, Kohler CA, McIntyre RS, Knochel C, Brunoni AR, Thase ME, Quevedo J, Fernandes BS, Berk M. Peripheral vascular endothelial growth factor as a novel depression biomarker: a meta-analysis. Psychoneuroendocrinology. 2015;62:18-26.

165. Tseng PT, Cheng YS, Chen YW, Wu CK, Lin PY. Increased levels of vascular endothelial growth factor in patients with major depressive disorder: a meta-analysis. Eur Neuropsychopharmacol. 2015;25:1622-30.

166. Krishnan V, Nestler EJ. Linking molecules to mood: new insight into the biology of depression. Am J Psychiatry. 2010;167:1305-20.

167. Hodes GE, Kana V, Menard C, Merad M, Russo SJ. Neuroimmune mechanisms of depression. Nat Neurosci. 2015;18:1386-93.

168. Medina A, Watson SJ, Bunney Jr W, Myers RM, Schatzberg A, Barchas J, Akil $\mathrm{H}$, Thompson RC. Evidence for alterations of the glial syncytial function in major depressive disorder. J Psychiatr Res. 2016;72:15-21.

169. Bremmer MA, Beekman AT, Deeg DJ, Penninx BW, Dik MG, Hack CE, Hoogendijk WJ. Inflammatory markers in late-life depression: results from a population-based study. J Affect Disord. 2008;106:249-55.

170. Paradise MB, Naismith SL, Norrie LM, Graeber MB, Hickie IB. The role of glia in late-life depression. Int Psychogeriatr. 2012;24:1878-90.

171. Hendricksen M, Thomas AJ, Ferrier IN, Ince P, O'Brien JT. Neuropathological study of the dorsal raphe nuclei in late-life depression and Alzheimer's disease with and without depression. Am J Psychiatry. 2004;161:1096-102.

172. Wilson RS, Nag S, Boyle PA, Hizel LP, Yu L, Buchman AS, Shah RC, Schneider JA, Arnold SE, Bennett DA. Brainstem aminergic nuclei and late-life depressive symptoms. JAMA Psychiat. 2013;70:1320-8.

173. Baldwin RC, O'Brien J. Vascular basis of late-onset depressive disorder. Br J Psychiatry. 2002;180:157-60.

174. Santos M, Kovari E, Gold G, Bozikas VP, Hof PR, Bouras C, Giannakopoulos P. The neuroanatomical model of post-stroke depression: towards a change of focus? J Neurol Sci. 2009;283:158-62.

175. Santos M, Gold G, Kovari E, Herrmann FR, Hof PR, Bouras C, Giannakopoulos P. Neuropathological analysis of lacunes and microvascular lesions in lateonset depression. Neuropathol Appl Neurobiol. 2010;36:661-72.

176. Xekardaki A, Santos M, Hof P, Kövari E, Bouras C, Giannakopoulos G. Neuropathological substrates and structural changes in late-life depression: the impact of vascular burden. Acta Neuropathol. 2012;124:453-64.

177. Lloyd AJ, Grace JB, Jaros E, Perry RH, Fairbairn AF, Swann AG, O'Brien JT, McKeith IG. Depression in late life, cognitive decline and white matter pathology in two clinico-pathologically investigated cases. Int J Geriatr Psychiatry. 2001;16:281-7.

178. O'Brien J, Thomas A, Ballard C, Brown A, Ferrier N, Jaros E, Perry R. Cognitive impairment in depression is not associated with neuropathologic evidence of increased vascular or Alzheimer-type pathology. Biol Psychiatry. 2001;49:130-6.

179. Thomas AJ, O'Brien JT, Davis S, Ballard C, Barber R, Kalaria RN, Perry RH. Ischemic basis for deep white matter hyperintensities in major depression: a neuropathological study. Arch Gen Psychiatry. 2002:59:785-92.

180. Tsopelas C, Stewart R, Savva GM, Brayne C, Ince P, Thomas A, Matthews FE. Neuropathological correlates of late-life depression in older people. $\mathrm{Br} \mathrm{J}$ Psychiatry. 2011;198:109-14. 
181. Wilson RS, Schneider JA, Bienias JL, Arnold SE, Evans DA, Bennett DA. Depressive symptoms, clinical AD, and cortical plaques and tangles in older persons. Neurology. 2003;61:1102-7.

182. Rapp MA, Schnaider-Beeri M, Grossman HT, Sano M, Perl DP, Purohit DP, Gorman JM, Haroutunian V. Increased hippocampal plaques and tangles in patients with Alzheimer disease with a lifetime history of major depression. Arch Gen Psychiatry. 2006;63:161-7.

183. Rapp MA, Schnaider-Beeri M, Purohit DP, Perl DP, Haroutunian V, Sano M. Increased neurofibrillary tangles in patients with Alzheimer disease with comorbid depression. Am J Geriatr Psychiatry. 2008;16:168-74.

184. Gunning-Dixon FM, Walton M, Cheng J, Acuna J, Klimstra S, Zimmerman ME, Brickman AM, Hoptman MJ, Young RC, Alexopoulos GS. MRI signal hyperintensities and treatment remission of geriatric depression. J Affect Disord. 2010;126:395-401

185. Olesen PJ, Gustafson DR, Simoni M, Pantoni L, Ostling S, Guo X, Skoog I. Temporal lobe atrophy and white matter lesions are related to major depression over 5 years in the elderly. Neuropsychopharmacology. 2010;35:2638-45.

186. Beekman AT. Neuropathological correlates of late-life depression. Expert Rev Neurother. 2011:11:947-9.

187. Sweet RA, Hamilton RL, Butters MA, Mulsant BH, Pollock BG, Lewis DA, Lopez OL, DeKosky ST, Reynolds 3rd CF. Neuropathologic correlates of lateonset major depression. Neuropsychopharmacology. 2004;29:2242-50.

188. Willner P. Validity, reliability and utility of the chronic mild stress model of depression: a 10-year review and evaluation. Psychopharmacology (Berl). 1997;134:319-29.

189. Fuchs E. Social stress in tree shrews as an animal model of depression: an example of a behavioral model of a CNS disorder. CNS Spectr. 2005;10:182-90.

190. Rygula R, Abumaria N, Flugge G, Fuchs E, Ruther E, Havemann-Reinecke U. Anhedonia and motivational deficits in rats: impact of chronic social stress. Behav Brain Res. 2005;162:127-34.

191. Bergstrom A, Jayatissa MN, Mork A, Wiborg O. Stress sensitivity and resilience in the chronic mild stress rat model of depression; an in situ hybridization study. Brain Res. 2008;1196:41-52.

192. Bouzinova EV, Norregaard R, Boedtkjer DM, Razgovorova IA, Moeller AM, Kudryavtseva O, Wiborg O, Aalkjaer C, Matchkov W. Association between endothelial dysfunction and depression-like symptoms in chronic mild stress model of depression. Psychosom Med. 2014;76:268-76.

193. Isingrini E, Surget A, Belzung C, Freslon JL, Frisbee J, O'Donnell J, Camus V, d'Audiffret A. Altered aortic vascular reactivity in the unpredictable chronic mild stress model of depression in mice: UCMS causes relaxation impairment to ACh. Physiol Behav. 2011;103:540-6.

194. Isingrini E, Belzung C, d'Audiffret A, Camus V. Early and late-onset effect of chronic stress on vascular function in mice: a possible model of the impact of depression on vascular disease in aging. Am J Geriatr Psychiatry. 2011;19:335-46.

195. Sun MK, Alkon DL. Cerebral ischemia-induced difference in sensitivity to depression and potential therapeutics in rats. Behav Pharmacol. 2013;24: 222-8.

196. Grizzell JA, Mullins M, larkov A, Rohani A, Charry LC, Echeverria V. Cotinine reduces depressive-like behavior and hippocampal vascular endothelial growth factor downregulation after forced swim stress in mice. Behav Neurosci. 2014:128:713-21.

197. Wharton SB, Simpson JE, Brayne C, Ince PG. Age-associated white matter lesions: the MRC Cognitive Function and Ageing Study. Brain Pathol. 2015; 25:35-43.

198. Schmidt R, Schmidt H, Haybaeck J, Loitfelder M, Weis S, Cavalieri M, Seiler S, Enzinger C, Ropele S, Erkinjuntti T, et al. Heterogeneity in age-related white matter changes. Acta Neuropathol. 2011;122:171-85.

199. Mettenburg JM, Benzinger TL, Shimony JS, Snyder AZ, Sheline YI. Diminished performance on neuropsychological testing in late life depression is correlated with microstructural white matter abnormalities. Neuroimage. 2012;60:2182-90.

200. Murphy ML, Frodl T. Meta-analysis of diffusion tensor imaging studies shows altered fractional anisotropy occurring in distinct brain areas in association with depression. Biol Mood Anxiety Disord. 2011;1:3.

201. Zou K, Huang X, Li T, Gong Q, Li Z, Ou-Yang L, Deng W, Chen Q, Li C, Ding $Y$, Sun $X$. Alterations of white matter integrity in adults with major depressive disorder: a magnetic resonance imaging study. J Psychiatry Neurosci. 2008:33:525-30

202. Choi KS, Holtzheimer PE, Franco AR, Kelley ME, Dunlop BW, Hu XP, Mayberg HS. Reconciling variable findings of white matter integrity in major depressive disorder. Neuropsychopharmacology. 2014;39:1332-9.
203. Bezerra DM, Pereira FR, Cendes F, Jackowski MP, Nakano EY, Moscoso MA, Ribeiz SR, Avila R, Castro CC, Bottino CM. DTI voxelwise analysis did not differentiate older depressed patients from older subjects without depression. J Psychiatr Res. 2012;46:1643-9.

204. Abe O, Yamasue H, Kasai K, Yamada H, Aoki S, Inoue H, Takei K, Suga M, Matsuo K, Kato T, et al. Voxel-based analyses of gray/white matter volume and diffusion tensor data in major depression. Psychiatry Res. 2010;181:64-70.

205. Valkanova V, Ebmeier KP. Vascular risk factors and depression in later life: a systematic review and meta-analysis. Biol Psychiatry. 2013;73:406-13.

206. Waloszek JM, Byrne ML, Woods MJ, Nicholas CL, Bei B, Murray G, Raniti M, Allen NB, Trinder J. Early physiological markers of cardiovascular risk in community based adolescents with a depressive disorder. J Affect Disord. 2015:175:403-10.

207. Paulson D, Bowen ME, Lichtenberg PA. Does brain reserve protect older women from vascular depression? J Gerontol B Psychol Sci Soc Sci. 2014;69:157-67.

208. Gothe F, Enache D, Wahlund LO, Winblad B, Crisby M, Lokk J, Aarsland D. Cerebrovascular diseases and depression: epidemiology, mechanisms and treatment. Panminerva Med. 2012;54:161-70.

209. Hybels CF, Pieper CF, Landerman LR, Payne ME, Steffens DC. Vascular lesions and functional limitations among older adults: does depression make a difference? Int Psychogeriatr. 2014;26(9):1501-9.

210. Smith GS, Kramer E, Ma Y, Kingsley P, Dhawan V, Chaly T, Eidelberg D. The functional neuroanatomy of geriatric depression. Int J Geriatr Psychiatry. 2009;24:798-808.

211. Kruglov LS, Meshandin IA. The optimization of therapy of old age patients with co-morbidity of depression and vascular psychoorganic disorders. Psychiatry Psychopharmacother. 2012;14:50-6.

212. Khalaf A, Edelman K, Tudorascu D, Andreescu C, Reynolds CF, Aizenstein H. White matter hyperintensity accumulation during treatment of late-life depression. Neuropsychopharmacology. 2015;40(13):3027-35.

213. Butters MA, Whyte EM, Nebes RD, Begley AE, Dew MA, Mulsant BH, Zmuda MD, Bhalla R, Meltzer CC, Pollock BG, et al. The nature and determinants of neuropsychological functioning in late-life depression. Arch Gen Psychiatry. 2004;61:587-95.

214. Tedeschini E, Levkovitz Y, lovieno N, Ameral VE, Nelson JC, Papakostas GI. Efficacy of antidepressants for late-life depression: a meta-analysis and meta-regression of placebo-controlled randomized trials. J Clin Psychiatry. 2011;72:1660-8.

215. Little JT, Reynolds 3rd CF, Dew MA, Frank E, Begley AE, Miller MD, Cornes C, Mazumdar S, Perel JM, Kupfer DJ. How common is resistance to treatment in recurrent, nonpsychotic geriatric depression? Am J Psychiatry. 1998;155:1035-8.

216. Bingham KS, Whyte EM, Meyers BS, Mulsant BH, Rothschild AJ, Banerjee S, Flint AJ. Relationship between cerebrovascular risk, cognition, and treatment outcome in late-life psychotic depression. Am J Geriatr Psychiatry. 2015;23:1270-5.

217. Kruglov LS, Meshandin IA. The relationships of cerebrovascular disease and depression in old age. Psychogeriatria Polska. 2013;10:91-102.

218. Iosifescu DV, Clementi-Craven N, Fraguas R, Papakostas GI, Petersen T, Alpert JE, Nierenberg AA, Fava M. Cardiovascular risk factors may moderate pharmacological treatment effects in major depressive disorder. Psychosom Med. 2005;67:703-6.

219. Fiedorowicz JG. Depression and cardiovascular disease: an update on how course of illness may influence risk. Curr Psychiatry Rep. 2014;16:492.

220. Thomas A, O'Brien JT. Management of late-life depression: a major leap forward. Lancet. 2015:386(10011):2374-5.

221. van Melle JP, de Jonge P. Beta-blocker use and the development of depression. Am J Cardiol. 2009:103:1331-2.

222. Luijendijk HJ, Koolman X. The incentive to publish negative studies: how beta-blockers and depression got stuck in the publication cycle. J Clin Epidemiol. 2012;65:488-92.

223. Baskys A. Pharmacogenomic information for common psychotropic drugs. In: Procyshyn RM, Bezchlibnyk-Butler KZ, Jeffries JJ, Procyshyn RM, Bezchlibnyk-Butler KZ, Jeffries JJ, editors. Clinical Handbook of Psychotropic Drugs. 21st ed. Boston: Hogrefe; 2015.

224. Kooistra M, van der Graaf Y, Grool AM, Zuithoff NP, Jan Biessels G, Geerlings MI. The natural course of elevated levels of depressive symptoms in patients with vascular disease over eight years of follow-up. The SMART-Medea study. J Affect Disord. 2016:202:95-101.

225. Harper DG, Joe EB, Jensen JE, Ravichandran C, Forester BP. Brain levels of high-energy phosphate metabolites and executive function in geriatric depression. Int J Geriatr Psychiatry. 2016. doi:10.1002/gps.4439.

226. Pennisi M, Lanza G, Cantone M, Ricceri R, Spampinato C, Pennisi G, Di Lazzaro V, Bella R. Correlation between motor cortex excitability changes 
and cognitive impairment in vascular depression: pathophysiological insights from a longitudinal TMS study. Neural Plast. 2016;2016:8154969.

227. Brunoni AR, Bensenor IM, Alves TC. Therapeutic interventions for vascular depression: a systematic review. Rev Bras Psiquiatr. 2011:33:400-9.

228. Peisah C, Snowdon J, Kril J, Rodriguez M. Clinicopathological findings of suicide in the elderly: three cases. Suicide Life Threat Behav. 2007;37:648-58,

229. Boldrini M, Hen R, Underwood MD, Rosoklija GB, Dwork AJ, Mann JJ, Arango $\mathrm{V}$. Hippocampal angiogenesis and progenitor cell proliferation are increased with antidepressant use in major depression. Biol Psychiatry. 2012;72:562-71.

230. Boldrini M, Santiago AN, Hen R, Dwork AJ, Rosoklija GB, Tamir H, Arango V, John MJ. Hippocampal granule neuron number and dentate gyrus volume in antidepressant-treated and untreated major depression. Neuropsychopharmacology. 2013;38:1068-77.

231. Tham MW, Woon PS, Sum MY, Lee TS, Sim K. White matter abnormalities in major depression: evidence from post-mortem, neuroimaging and genetic studies. J Affect Disord. 2011;132:26-36.

232. Taylor WD, Benjamin S, McQuoid DR, Payne ME, Krishnan RR, MacFall JR, Ashley-Koch A. AGTR1 gene variation: association with depression and frontotemporal morphology. Psychiatry Res. 2012;202:104-9.

233. Krishnan KR, McDonald WM. Arteriosclerotic depression. Med Hypotheses. 1995:44:111-5

\section{Submit your next manuscript to BioMed Central and we will help you at every step:}

- We accept pre-submission inquiries

- Our selector tool helps you to find the most relevant journal

- We provide round the clock customer support

- Convenient online submission

- Thorough peer review

- Inclusion in PubMed and all major indexing services

- Maximum visibility for your research

Submit your manuscript at www.biomedcentral.com/submit 